Florida International University FIU Digital Commons

FIU Electronic Theses and Dissertations

University Graduate School

5-5-2007

\title{
Substance Use and Sexual Risk Behaviors among Adolescent Detainees
}

Patria Rojas

Florida International University, patria.rojas@fiu.edu

DOI: $10.25148 /$ etd.FI08081542

Follow this and additional works at: https://digitalcommons.fiu.edu/etd

\section{Recommended Citation}

Rojas, Patria, "Substance Use and Sexual Risk Behaviors among Adolescent Detainees" (2007). FIU Electronic Theses and Dissertations. 34.

https://digitalcommons.fiu.edu/etd/34

This work is brought to you for free and open access by the University Graduate School at FIU Digital Commons. It has been accepted for inclusion in FIU Electronic Theses and Dissertations by an authorized administrator of FIU Digital Commons. For more information, please contact dcc@fiu.edu. 


\section{FLORIDA INTERNATIONAL UNIVERSITY}

Miami, Florida

\section{SUBSTANCE USE AND SEXUAL RISK BEHAVIORS AMONG ADOLESCENT DETAINEES}

A dissertation submitted in partial fulfillment of the requirements for the degree of DOCTOR OF PHILOSOPHY

in

SOCIAL WELFARE

by

Patria Rojas 
To: Dean Ray Thomlison

College of Social Work, Justice and Public Affairs

This dissertation, written by Patria Rojas, and entitled Substance Use and Sexual Risk Behaviors among Adolescent Detainees, having been approved in respect to style and intellectual content, is referred to you for judgment.

We have read this dissertation and recommend that it be approved.

Mark Macgowan

Robert Malow

Barbara Thomlison

Christopher P. Rice, Major Professor

Date of Defense: May 10, 2007

The dissertation of Patria Rojas is approved.

Dean Ray Thomlison College of Social Work, Justice and Public Affairs

Dean George Walker University Graduate School

Florida International University, 2007 
C Copyright 2007 by Patria Rojas

All rights reserved. 


\section{DEDICATION}

This dissertation is dedicated to Mario because his unconditional love was a necessity during this journey. I would also like to dedicate this dissertation to my father and my mother, whose admirable strength and work ethic have always been an example to follow. I am also dedicating this dissertation to Mina because her guidance and unconditional care for my intellectual and personal development have been fundamental in my life. Finally, this dissertation is dedicated to my sister Yokasta and my brothers

Diego, Tony, Stalin, Darin, Martin, and my brothers by choice Juan G. Rozon, and Jorge A. Rozon who have always believed in me and in my aspirations. 


\section{ACKNOWLEDGMENTS}

I would like to thank my major professor Dr. Christopher Rice for his guidance, knowledge, patience, and great sense of humor, all of which were essential during my time at Florida International University. I would also like to thank all the professors in the committee for their encouragement, time, and helpful advice, especially Dr. Barbara Thomlison. I really appreciate Dr. Mark Macgowan for his skillful guidance, significant support throughout the development of my study, and his genuine interest in my work. I would also like to recognize Dr. Robert Malow because of his valuable support, his enthusiasm, sense of humor and dedication to mentoring. His support has been critical during this process. 


\title{
ABSTRACT OF THE DISSERTATION \\ SUBSTANCE USE AND SEXUAL RISK BEHAVIORS \\ AMONG ADOLESCENT DETAINEES
}

\author{
by
}

Patria Rojas

Florida International University, 2007

Miami, Florida

Professor Christopher P. Rice, Major Professor

There is a commonly presumed link among sexual risk behavior, substance use, and other psychosocial factors among adolescents. However, these relationships have been relatively understudied in detained, low-income, minority, substance abusing adolescents. This study addresses this gap in the literature with a secondary data analysis based on a sample of adolescent offenders in two detention and treatment centers in Miami-Dade County. Univariate, bivariate statistical analysis and multivariate logistic regressions were conducted on baseline data from structured interviews with 455 adolescents participating in an NIH funded prevention intervention. Data were analyzed to assess relationships among self-reported substance use, STD history, HIV/AIDS knowledge, condom use, condom use attitudes, and skills, peer and parental approval to use condoms, and race/ethnicity.

The adolescent sample was $74.1 \%$ male, and $25.9 \%$ female and $35.4 \%$ African American, 25.1\% non-African American Latino, 11.2\% White, and 28.4\% of other race/ethnicity categories. The mean age was 15.6 years. 
Results suggested that alcohol use $(\mathrm{p}<0.001)$ and use of marijuana, cocaine and other drugs $(\mathrm{p}<0.001)$ are significant variables when explaining the variability in sexual risk behaviors. Results also suggested that unprotected vaginal, anal, and oral sex increased with higher alcohol and drug use $(\mathrm{p}<0.001)$ and that positive attitudes about personally using condoms ( $\mathrm{p}<0.001)$ were also significantly related to condom use. Logistic regressions showed that race/ethnicity was a significant control variable when explaining the variability of condom use. Being White and Latino were significantly associated with less condom use during oral and anal sex when compared to other racial/ethnic groups. These results indicated that risky sexual behavior and HIV infection risk are significantly associated with substance use, particularly alcohol use. Therefore, proper screening and identification of alcohol use, and condom use attitudes could maximize the efficacy of referrals to programs targeting both issues and increase the potential for appropriate primary and secondary prevention and treatment among adolescent detainees. 


\section{TABLE OF CONTENTS}

CHAPTER

PAGE

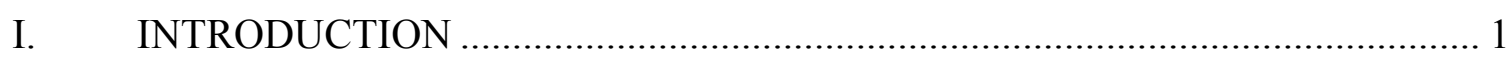

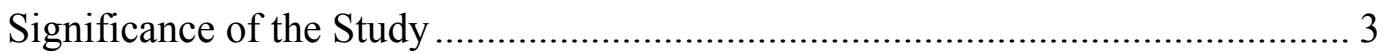

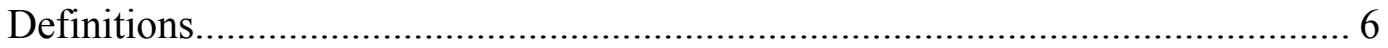

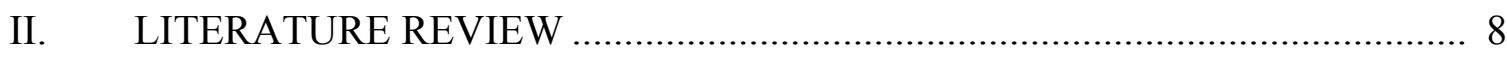

Scope of the Risky Sexual Behavior Problem Among Adolescents....................... 8

Prevalence of HIV/AIDS and other STD among Adolescent Detainees.............. 14

Influence of Alcohol, Illicit Drugs, HIV/AIDS

and other STD on Condom Use among Detained Adolescents ............................ 17

Condom Use: Parental and Peer Approval ......................................................... 24

Adolescents' Attitudes Toward the use of Condoms........................................... 29

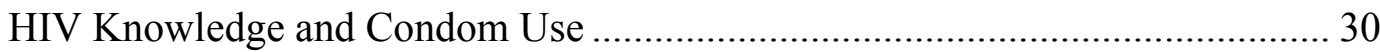

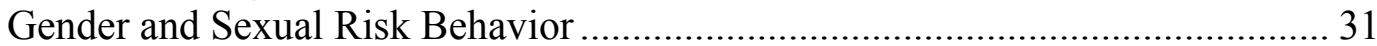

Research Questions .....................................................35

Theories and Models Used to Understand Adolescents Sexual Behaviors ......... 36

Health Belief Model ....................................................... 37

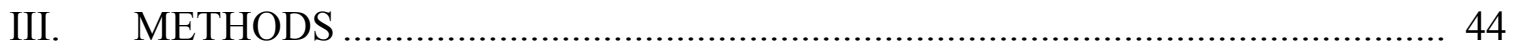

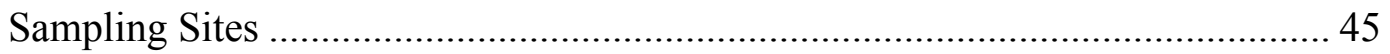

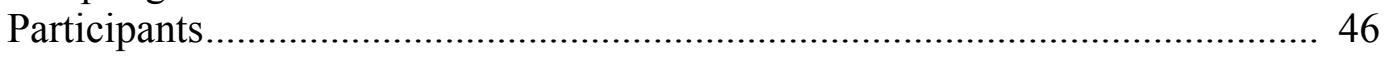

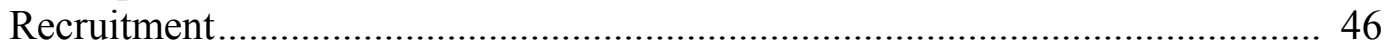

Assessment Measures ……………………………................................... 47

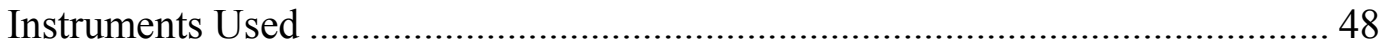

Data Analyis Strategies................................................................................. 52

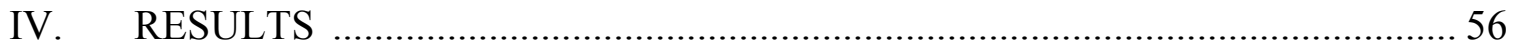

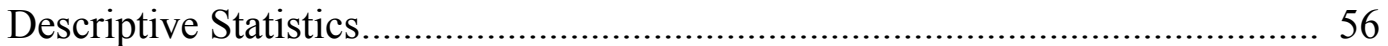

Logistic Regression Analysis: Fitting the Model..................................................... 60

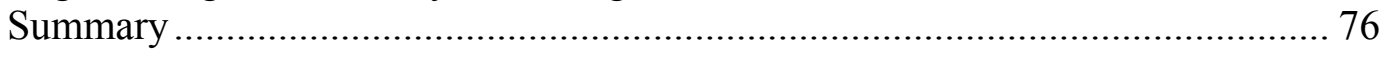

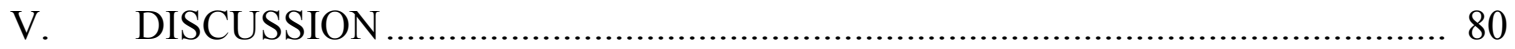

Discussion of Results ........................................................................... 80

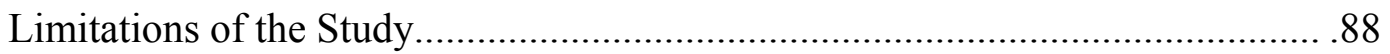

Implications for Social Work and Public Health Policy.................................... 90

Implications for Social Work and Public Health Practice .................................. 94

Implication for Future Research ................................................................... 99

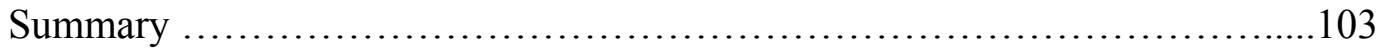

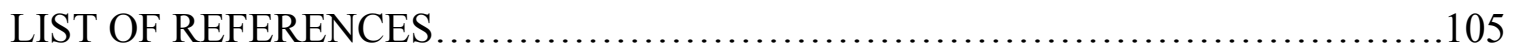

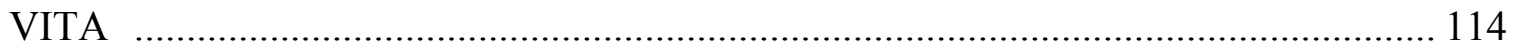




\section{LIST OF TABLES}

TABLE

PAGE

1. AIDS and HIV Cases in Miami-Dade County in 2003........................................... 11

2. Variable List, Measures, and Statistical Analyses .................................................. 54

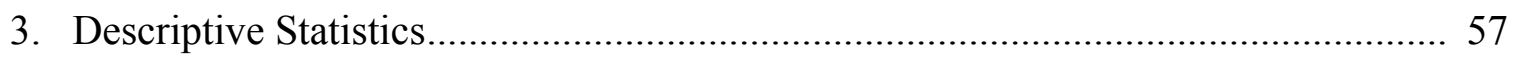

4. Among Adolescent Detainees the Association of Alcohol and Drug Use with Not Using a Condom for Vaginal Sex When Controlling for Gender and Race/Ethnicity.....

5. Among Adolescent Detainees the Association of Alcohol and Drug Use with Not Using a Condom for Oral Sex When Controlling for Gender and Race/Ethnicity.... 64

6. Among Adolescent Detainees the Association of Alcohol and Drug Use with Not Using a Condom for Anal Sex When Controlling for Gender and Race/Ethnicity ... 65

7. Among Adolescent Detainees the Association of Attitudes and Knowledge Indicators with Not Using a Condom for Vaginal Sex When Controlling for Gender and Race/Ethnicity

8. Among Adolescents Detainees the Association of Attitude and Knowledge Indicators with Not Using a condom for Oral Sex When Controlling for Gender and Race/Ethnicity

9. Among Adolescents Detainees the Association of Attitude and Knowledge Indicators with Not Using Condom for Anal Sex when Controlling for Gender and Race/Ethnicity

10. Among Adolescent Detainees the Association of Peer and Parental Approval, Alcohol Use and Drug Use with Not Using a Condom for Vaginal Sex when Controlling for Gender and Race/Ethnicity

11. Among Adolescent Detainees the Assocition of Peer and Parental Approval, Alcohol Use and Drug Use with Not Using a Condom for Oral Sex When Controlling for Gender and Race/Ethnicity

12. Among Adolescent Detainees the Association of Peer and Parental Approval, Alcohol Use and Drug Use with Not Using a Condom for Anal Sex When Controlling for Gender and Race/Ethnicity 


\section{ACRONYMS AND ABBREVIATIONS}

AFPA

AFPE

AIDS

BART

$\mathrm{CDC}$

$\mathrm{FDOH}$

HARDDRUG

HBM

HIV

IV

JAC

MTFS

$\mathrm{NIH}$

NIDA

OHUSE

STD

TB

YRBS
Parent approval to use condoms

Peer approval to use condoms

Acquired Immunodeficiency Syndrome

Becoming a Responsible Teen

Center for Disease Control

Florida Department of Health

Marijuana, cocaine and other drugs

Health Belief Model

Human Immunodeficiency Virus

Intravenous drug use

Juvenile Assessment Center

Monitoring the Future Survey

National Institutes of Health

National Institute of Drug Abuse

Alcohol use

Sexually transmitted diseases

Tuberculosis

Youth Risk Behavior Survey 


\section{CHAPTER I}

\section{INTRODUCTION}

During the past two decades there has been much research conducted on the relationship between the risky sexual behavior practices and substance use among U.S. adolescents. This body of research has documented the fact that substance use and not using condoms are the most important indicators associated with the risk of becoming infected with sexually transmitted diseases (STD) both among adolescents and adults (Florida Department of Public Health, 2004; Malow, Devieux, Jennings, \& Lucenko, 2001; McCoy \& Inciardi, 1995). Data from those reports and studies indicate that adolescents and adults who use a condom regularly and appropriately are 20 times less likely to contract an STD than those who do not (Pinkerton \& Abramson, 1997).

However, less empirical evidence exists about the factors that influence adolescent use of condoms, particularly among adolescents who are detained due to their criminal lifestyle. Researchers have found both a high prevalence of STD in addition to early onset of sexual activity without protection among some adolescent groups such as the detainees (D'angelo \& DiClemente, 1996) and that adolescents tend to underestimate their risks of acquiring the human immunodeficiency virus (HIV) (Magura, Shapiro, \& Kang, 1994). Many adolescents will experiment with alcohol and other drugs. This behavior may compromise their judgment and increase their chances of engaging in risky sex (Rotheram-Borus, 2000). Hence the need for research that investigates the influence that substance use, risky sexual attitudes, knowledge about the transmission of HIV, and both peer and parental approval of condom use have on the use of condoms among both female and male adolescent detainees. Lastly, it is important for additional research to be 
conducted because adolescent detainees have been identified as being at high risk of becoming infected with an STD (Malow, Rosemberg, \& Devieux, 2006).

The purpose of this study was to examine the relationship among adolescent substance use, gender, sexual risk attitude, attitude about personal use of condoms, knowledge associated with the transmission of HIV, peer and family approval of condom use, history of sexually transmitted diseases (STD) and the level of condom use in a sample of adolescents housed in a correctional institution. Further details of the explanatory variables, the control variables and their expected relationships can be found in the review of the Literature in Chapter 2. Also, more information about the separate analysis of the research questions is detailed in the Methods section in Chapter 3.

Based on the literature detailed in Chapter 2 (e.g., Malow et al., 2006), the current study's researcher anticipated that adolescents' higher levels of illicit drug use would be related to higher levels of sexual risk behaviors, as measured by lower levels of condom use, than their counterparts who used no drugs. Similarly, it was hypothesized that positive attitudes toward condom use and higher levels of HIV risk knowledge would be associated with a lower level of risky sexual behaviors along with a higher level of condom use skill. It was further hypothesized that the level of approval perceived from parents and peers regarding condom use was going to be related to adolescents' safe sex behavior (i.e., condom use). Therefore, it was expected that participants' perception of a high level of approval to use condoms from peers and parents would be a statistically significant variable in helping explain the condom use within this sample of adolescent detainees. 


\section{Significance of the Study}

The current study is significant along several dimensions. First, at present there is a dearth of research that has examined the influencing factors associated with detained adolescents' use of condoms. It is important to better understand what is associated with condom use with this group because at least one study on risk factors associated with STD among juvenile delinquents indicated that adolescents in detention centers were more likely than their high school peers to report engaging in risky sexual practices such as sex with three or more partners, unprotected sexual activity, and exchanging sex for money (Canterbury, McGarvey, Sheldon-Keller, \& Reams, 1995).

This current study also contributes to the field by providing additional information on the relationship between condom use and substance use among detained adolescents. Detained adolescents comprise a subset of the delinquent adolescent population; hence, this group of detained adolescents exhibits a high prevalence of substance abuse in addition to a high level of sexual risk behaviors. Consequently, this population subgroup is at great risk for contracting HIV and other sexually transmitted diseases such as chlamydia. Taken as a group, adolescent detainees returning to the community have the potential to be a primary source of STD transmission if their prevalence of risky sexual behaviors and_substance use are not reduced. While there are interventions that have had a positive effect on these behaviors in other segments of the adolescent population, not much is known about how to successfully implement these interventions among ethnic/racial minority adolescents and detained or incarcerated adolescents. 
Furthermore, although many studies have researched the sexual risky behavior of adolescents, very few have included Latinos in their minority samples. The contributions of the current study, which does so, to the literature are important given that Latinos are the largest and fastest growing minority population in the U.S. (Census, 2006). According to the Centers for Disease Control (CDC), current trends also indicate that, in the future, Latino HIV/AIDS and STD rates could increase to match or exceed infection rates among the African American population (Center for Disease Control and Prevention \& National Center for HIV/STD and TB prevention, 2004). In addition, the relationship between substance use and STD history specifically among minority detained adolescent detainees remains partly unexplored. This gap in research is particularly significant among adolescent detainees of Latino descent. One of the primary foci of the present study was to address this gap.

The current study's inclusion of a large number of Latino and African American participants and employ of measures validated for use with minority groups makes it a valuable contribution to the literature on detained adolescents. In addition, the present study adds to the research findings of previous studies on substance abuse and minority youth, and may help guide future research concerning minority adolescent offenders. In addition, the current study, the investigation of the relationship of race/ethnicity, levels of peer and parental condom use approval, and the use of condoms among this sample of adolescent detainees may inform practitioners of treatment interventions at the local public health department and social service agencies providing services to this population. 
Finally, the results of the current study may aid in the development of social work prevention programs targeting at-risk adolescents in the city of Miami, a population who, for the most part, will eventually be released back into their communities. Findings from the current study could subsequently be the basis for developing more effective strategies to reduce the rate of risky sexual behaviors among adolescents living in Miami, a city which ranks number one in the state for infectious syphilis and number two for chlamydia among adults (Florida Department of Health, 2004) These strategies may include making changes to the existing standardized screening, referral, and treatment protocols currently used in providing substance use and STD prevention to minority incarcerated or detained adolescents. For example, the re-design of protocols to assess drug use so that they include assessment of sexual risk behaviors, may help provide a more thorough evaluation of the health status of incarcerated or detained juveniles. Additionally, the results from the current study could be of help and reference for local public health practitioners and may inform local policy advocates who support regulations regarding the drug use and its relationship with risky sexual behaviors among juvenile detainees in Miami-Dade County. Furthermore, funding mechanisms for drug prevention programs may need to consider requiring juvenile detention centers to work in collaboration with HIV/AIDS prevention programs.

Moreover, it is difficult to create policies and provide HIV/AIDS and STD prevention intervention to at-risk populations such as incarcerated or detained juveniles because there is no mechanism in place to motivate them toward long term behavioral changes (McCoy \& Inciardi, 1995). To add to this difficulty, the perception of public health policy practitioners is that some of the juveniles being studied may be incorrigible 
and so unable to engage in, let alone sustain, long term healthy behaviors. However, there have been many studies done on the implementation of secondary prevention among atrisk populations in which resources and brief skill development intervention have been shown to decrease the number of sexual partners and reduce other sexual risk behaviors among substance users (MacCoy \& Inciardi, 1995, p.129). Studies such as this one are designed to help meet the need to continue finding more effective prevention interventions for this population of adolescents.

\section{Definitions}

For the purpose of the current study, substance use was defined as any number of times the adolescent participants used drugs (alcohol, marijuana, cocaine, and other drugs) during the past 6 months. Although the use of alcohol is not prohibited for adolescents, Illicit drugs refers to marijuana, cocaine and other drugs that are illegally used by adults. Sexually risky behavior refers to having vaginal, oral, and anal sex without using a condom or using a vaginal dam during oral sex on females. The variable was formed by dividing the number of times participants used condoms during sex into the number of times they engaged in the different sexual behaviors during the same timeframe (vaginal, oral, and anal). Sexual risk attitudes refer to how participants felt about engaging in safe sex, while condom use attitudes was defined as the participants' attitudes toward their own (or their partner's) use of condoms. HIV knowledge refers to participants' knowledge of facts about HIV transmission. Additionally, STD was defined as any lifetime diagnoses of a sexually transmitted disease.

The term detained adolescents in describing the current study's sample refers to adolescents who have been processed by the Juvenile Assessment Center in Miami-Dade 
County and are waiting to have their cases presented to the judge. As with all detained adolescents, these individuals are a subset of delinquent adolescents waiting for their cases to be adjudicated. Those found guilty will be sentenced and sent to a juvenile correctional facility. Further, concerning appropriate racial/ethnic labels for this population, researchers have used the terms Hispanic and Latino interchangeably. In the current study, the term Latino was used to refer to individuals of Cuban, Puerto Rican, Mexican, and Central or South American descent. Additionally, the terms African American and Black have been used interchangeably in different studies. However, in the current study, only the term African American was used. Finally, since the present study was based on a secondary analysis of data from a National Institute of Drug Abuse (NIDA) funded project, the original NIDA funded study has been referred as the parent study. Further explanations of these definitions and other variables can be found in Chapter 3. 


\section{CHAPTER II}

\section{LITERATURE REVIEW}

The following review of the literature is organized along two aspects. One aspect focuses on what is known about the scope of HIV/AIDS and other STD among adolescents, particularly adolescents detainees, and examines the relationship between substance use and risky sexual behaviors. The other aspect deals with the gaps in research areas that are addressed by the current study. This second aspect is composed of nine dimensions that include: (a) problems regarding HIV/AIDS and STD among adolescents in the United States and specifically in Miami, Florida; (b) the prevalence of STD and HIV/AIDS among adolescents and adolescent detainees in the United States including Miami, Florida; and (c) the influences that the use of alcohol, marijuana, cocaine, and other drugs have on the use of condoms and on the rate of HIV/AIDS and other STDs among delinquent and detained adolescents; (d) the relationship among condom use and perceived parental and peer approval to use condoms; (e) adolescents' attitudes toward the use of condoms; (f) the relationship between HIV knowledge and condom use; (g) the relationship between gender and sexually risky behavior; and (h) the use of theories and models to understand detained adolescents' risky sexual behavior; and (i) an overview of the Health Belief Model which is the model guiding the analysis of the current study. Scope of the Risky Sexual Behavior Problem Among Adolescents

\section{HIV/AIDS: The National Problem}

Results from several national surveys on adolescent health indicate that recently, an increasing number of individuals have been diagnosed with HIV/AIDS in the U.S. and in particular in Miami, Florida (Center for Disease Control and Prevention \& National 
Center for HIV/STD and TB prevention, 2004). This trend has resulted in a high prevalence of HIV/AIDS among adolescents in the United States. Evidence of this development was presented in 1999 CDC data that showed that from 1993 to 1999, the number of adolescents with HIV increased dramatically in the U. S. (34\% increase), making AIDS a leading cause of death among male and female youth in the 15 to 24 year age range (Kingree \& Betz, 2003; Rotheram-Borus, 2000). Further, in 2002, the Center for Disease Control (CDC) reported that at least $50 \%$ of all new HIV infections in the United States were among adolescents or young adults under the age of 25 who primarily acquired the virus through unprotected sexual intercourse (Center for Disease Control Division of HIV/AIDS Prevention, 2002a).

Specifically, historical data from the CDC (Center for Disease Control and Prevention \& National Center for HIV/STD and TB prevention, 2004) indicate that from 1985 to 1999 the proportion of AIDS cases reported in the U.S. among young adult and adolescent women more than tripled ( $7 \%$ to $25 \%$ ), and the majority of cases were among young African-American and Latino women. By 2005, African American and Latino adolescents accounted for $66 \%$ and $21 \%$ respectively of the reported adolescent AIDS cases in the U.S. (National Institute of Allergy and Infection Diseases, 2005). Taken together these figures indicate that nationwide, there is a growing problem of adolescent HIV infection, in particular among minority youth.

A related cause for concern is the fact that the literature reveals that African American and Latino adolescents are more likely to engage in both safe and unsafe sexual activities than their White counterparts (60.8\%, $48.4 \%$, and $43.2 \%$ respectively) (Irwin, Charles, Burg, \& Uhler-Cart, 2002). These findings are supported by a major 
epidemiologic study by other researchers (Villaruel \& Rodriguez, 2003) as well as by the Youth Risk Behavior Survey. Both studies indicated a slightly lower incidence of early sexual behavior as well as lower pregnancy rate among White non-Hispanic adolescents in the U.S.. Among Latino and African American adolescents, trends continue to indicate high rates of pregnancy and sexually transmitted diseases (Center for Disease Control and Prevention, 2002; Center for Disease Control Division of HIV/AIDS Prevention, 2000).

Related to the rise in the number of adolescents diagnosed with AIDS, during the past two decades epidemiologic research has documented that sexual risk behaviors (e.g., lack of condom use) have been associated with considerable morbidity among adolescents (Center for Disease Control and Prevention, 2006). That research has concluded that unprotected sex is one of the major risk factors associated with the increasing rate of HIV/AIDS in the United States (including Miami-Dade County) in the past 15 years.

\section{HIV/AIDS in Miami-Dade}

The impact of engaging in risky sexual behaviors among adolescents in the Miami area is great. The Florida Department of Health (2003) has estimated that one in four people living in Florida with AIDS acquired HIV while they were adolescents. Data from the CDC indicate that in 1999, Miami had the nation's third highest AIDS rate. By 2003, Miami reached second highest rate $(45.8$ per 100,000) followed by San Francisco $(45.2$ per 100,000) (Florida Department of Health, 2004, pp. 3-4). CDC data have further indicated that most of those people have acquired HIV through having unprotected sex with an infected partner (Center for Disease Control and Prevention \& National Center for HIV/STD and TB prevention, 2004). In 2003, Miami-Dade County's AIDS case rate 
was the highest in the state (Center for Disease Control and Prevention National Center for HIV STD and TB prevention, 2003; Florida Department of Health, 2003). As shown in Table 1, the percentages of AIDS cases in Miami-Dade in 2003 among Whites, African Americans, and Latinos differed significantly.

It is generally accepted that the numbers of HIV positive cases are underreported in the county and state. Specifically, in Miami-Dade, it has been estimated that only $10 \%$ of the new HIV infections in 2002 occurred among adolescents. However, given the higher rate $(50 \%)$ noted nationally, this prevalence is probably underestimated. Equally important, those figures likewise reflect a greater percentage of African American individuals than persons of other races/ethnicities.

Table 1. AIDS and HIV Cases in Miami-Dade County in 2003

\begin{tabular}{lcc}
\hline Race/Ethnicity & Number of Cases & Percent of Total Cases \\
\hline African American & 4,224 & $39 \%$ \\
Latino & 3,651 & $33 \%$ \\
White & 1,734 & $16 \%$ \\
Other & 1,153 & $12 \%$ \\
Total & 10,762 & $100 \%$
\end{tabular}

Note. Adapted from data from the CDC, 2002. (Center for Disease Control Division of HIV/AIDS Prevention, 2002a)

From 1998-2000 the average number of deaths per year in Miami Dade county due to AIDS among African-Americans was 325, while it was 206 among Latinos (Center for Disease Control Division of HIV/AIDS Prevention, 2002b). However, this pattern may change in the future because the HIV rate of infection among Latinos in the 
Miami area has increased at a faster pace than that of African Americans (Center for Disease Control, 2004). In addition, it should be noted that according to the latest U.S. Census, $49 \%$ of the adolescents living in Miami Dade are Latinos (United States Census, 2000) this means that demographically, the Miami area has a critical need to find effective public health measures for this large and growing population of Latino adolescents. This concern is reflected across the U.S. as well. Nationally, in the 5 year period between 1997 and 2001, Latinos' HIV rate increased from 29\% of the total reported cases in 1997 to 33\% of the total reported cases in 2001(Center for Disease Control and Prevention, 2001).

Moreover, recent data from the $\mathrm{CDC}$ provide additional evidence of an HIV/AIDS epidemic among African Americans and Latinos in the U.S. and in particular in Miami, Florida. Many of the new cases are associated with the use of alcohol and other drugs and unprotected heterosexual sex (CDC, 2006; Miami Dade County Health Department, 2006). Additionally, gender and age are reported to be important moderators in the reported AIDS cases in Miami-Dade County; adolescent girls and adult women together comprise $60 \%$ of all the AIDS reported cases there and $53 \%$ of them are adolescents. Therefore, adolescent females compromise a larger percentage than adults in this group. Given that females have higher infection rates than their male counterparts and that among females, adolescents have a higher risk of infection of HIV and other STDs, better research based practices must be developed to address how to intervene and teach this vulnerable population how to negotiate the use of condoms with their male partners. By extension from these findings with adolescents in general, HIV infection and other STDs are health risks that the young sexually active juvenile delinquent population 
in Miami-Dade faces. Further research is needed to address the serious combination of a high incidence of STD plus delinquent adolescents' documented high rate of unprotected sex.

The problem of risky sexual behavior is a serious one, particularly in Miami because here the HIV exposure is generally related to having unprotected sex with an infected intravenous drug user, and engaging in high risk sexual behaviors while under the influence of drugs or alcohol (William Stern et al., 2001). Another part of the scope of the sexually risky behavior problem is that although engaging in unprotected sex is known to be one of the major contributing factors for STD and HIV infection among adolescents, recently, $57 \%$ of adolescents in Florida diagnosed with HIV did not identify it as a risk factor for infection (Florida Department of Public Health, 2004). Prevalence of other STD among Adolescents Nationally and in Miami-Dade County

Unlike the increasing HIV/AIDS epidemic in the United States, research indicates that there has been a slight decline in the rates of other STDs such as chlamydia, gonorrhea, and syphilis among U.S. White non-Hispanic adolescents (Center for Disease Control and Prevention, 2000; Center for Disease Control Division of HIV/AIDS Prevention, 2002a). However, epidemiologic research has also documented that when compared to adult rates; the adolescent rate of STD is still higher for infections such as chlamydia, gonorrhea, and the human papiloma virus (Center for Disease Control and Prevention National Center for HIV STD and TB prevention, 2004). Similarly to HIV infection, unprotected sex is a major risk factor associated with STD infection among adolescents (American Academy of Pediatrics, 2001). 
In 2001, Miami-Dade reported rates of syphilis that were higher than the Healthy People 2002 objectives ( 0.2 per 100,000 population). The county was one of the five counties in the state with the highest primary and secondary syphilis rates. Adding to the problem of STD in the state, cumulative statewide data (Florida Department of Health, 2004) indicate that the rate of syphilis infections among adolescents in general (from all races) has not decreased significantly since 2003 (i.e., rates declined from 25.8 per 100,000 in 2001 to 22.58 in 2003).

Furthermore, in 2003 the rates of chlamydia and gonorrhea among adolescents were $4.5 \%$ and $3.7 \%$ respectively higher than the rates of these sexually transmitted diseases in the adult population of Miami-Dade. From 2000 to 2001 there was actually an increase in the chlamydia rates in Miami Dade. In 2002, Florida reported 33,482 cases of chlamydia and Miami Dade had the highest incidence rate in the state with 4, 711 cases (Florida Department of Health, 2004). The general population's gonorrhea rate in MiamiDade in 2001 was more than 300 cases per 100,000 population (Center for Disease Control and Prevention National Center for HIV STD and TB Prevention, 2004). This rate was almost three times higher than the national rate of 125 (per 100,000) for the general population. It was also much higher than the 2002 reported rate of gonorrhea cases in the entire state of Florida; 133.6 (per 100,000 population).

Prevalence of HIV/AIDS and other STD among Adolescent Detainees

There are less data documenting trend and prevalence on the HIV and STD rates of adolescent detainees in the United States, including those in Miami, Florida, than any other adolescent sub-group. This may well be related to the fact that there have been fewer studies focusing on juvenile delinquents and detainees than on adolescents in the 
community, e.g. high school students. However, there are studies that have indicated that the rates of STD among detained adolescents are higher than that of the general population (Inciardi, 1996). In addition, STD rates have been found to be higher among female adolescent detainees than among their male counterparts. Unfortunately, the large studies such as the National Youth Surveys do not include detained adolescents. Therefore, this at-risk population has been included only in smaller scale studies from which generalizability needs to be done carefully.

Regarding STD, while data on the rates of chlamydia, gonorrhea, and syphilis among juvenile delinquents are limited, a CDC survey that collected information on STD rate among juveniles in detention centers indicated a high prevalence of STD among them (CDC, 2004). The higher rates of chlamydia, gonorrhea, and syphilis among juvenile delinquents was not surprising, given the fact that a number of studies have noted a higher rate of sexual risk behaviors among juvenile delinquents compared to the general adolescent population (Irwin, Charles, Burg, \& Uhler-Cart, 2002; Kingree \& Betz, 2003; Kingree, Braithwaite, \& Woodring, 2000; Kingree \& Phan, 2001). In MiamiDade, the Juvenile Assessment Center (JAC; 2004) came to a similar conclusion. The JAC found high rates of STD in its juvenile detention population. Especially relevant to that finding is the fact that one study reported adolescent delinquents in Miami-Dade have an extra risk factor since they live in communities where sexually transmitted diseases have epidemic rates (Kipke, 1999).

Further, in a national sample of female detainees, the Reproductive Health Monitoring Project (Center for Disease Control \& National Center for HIV STD and TB Prevention, 2004; Sterk, 2002), indicated the median rate for chlamydia among detained 
female adolescents was $14.8 \%$, which was 10.3 percentage points higher than for incarcerated adult women.

In another study (Canterbury, McGarvey, Sheldon-Keller, \& Reams, 1995) done in selected urban areas involving incarcerated adolescents, the researchers examined HIV infection, risky behaviors, and STD history. The researchers sampled 1,215 medical records of African American (69\%) and White (31\%) youths coding them for gender, race/ethnicity, and current diagnosis of chlamydia, gonorrhea, pediculosis pubis, and trichomonas. The adolescent males in that study reported risky sexual behavior that put them at risk of acquiring STD and HIV, including having sex with three or more partners, engaging in unprotected sexual activity, and exchanging sex for money. The results of that study indicated that $76 \%$ of the participants had been involved with three or more sexual partners. Further, $19 \%$ of all the participants reported a past history of STD. Of the female participants (11\% of the sample), $44 \%$ reported a past history of STD indicating that a high rate of STD among detained adolescent females (Canterbury et al., 1995).

Part of the strength of the Canterbury and colleagues' (1995) study lies in its large sample size, permitting researchers some confidence interpreting the results that incarcerated adolescents are at high risk for STD and HIV infection. However in addition to the lack of Latinos in its sample, another limitation of the Canterbury and colleagues' (1995) study is that although $79 \%$ of the participants reported using condoms when engaging in sex, the frequency of their correct and consistent condom use is unknown. Hence, some degree of caution must be exercised when generalizing from the Canterbury et al. study. Its limitations and gaps invite further investigation. 
In Miami, Florida, the setting of this study, data collected by the Juvenile Assessment Center (JAC) of Miami, a facility that processes adolescent delinquents when they are first arrested, also suggests that adolescent detainees have an extremely high risk of acquiring STD (Morris, Harrison, Knox, \& Tromanhauser, 1995). Although there is not much information on the rates of STD and HIV among adolescent detainees in Miami-Dade; it has been reported that female adolescent detainees in Miami-Dade have a high rate of STD that is even higher for recidivists. Adolescent female recidivists are 13.92 more likely to have an STD than their non-recidivist peers (Lederman, Dakof, Larrea, \& Hua, 2004).

Influence of Alcohol, Illicit Drugs, HIV/AIDS and other STD on Condom Use among Detained Adolescents

Alcohol, marijuana and other drugs have been generally associated with sexual risk taking behaviors of adolescents (Tapert, Aarons, Sedlar, \& Brown, 2001). As in previous research on White non-Latino adult populations, researchers are beginning to find that substance use does have a modifying effect on the sexual risk behaviors of adolescent detainees, primarily on their use of condoms during sexual intercourse. Substance use has been found to have a relationship with high risk sexual behaviors among young adults. Substance users have been found to have more frequent casual sex, less use of condoms, and higher rates of unplanned pregnancies (Tapert, Aarons, Sedlar, \& Brown, 2001. Since the early 1990s the high rates of HIV/AIDS and other STD among juvenile delinquents nationwide and in Miami, Florida were thought to be related to the substance use behaviors found among these adolescents (Dembo, Schmeidler, Chin Sue, \& Borden, 1998; Dembo, Williams, La voie, Schmeidler, Kern et al., 1990). Actually, 
substance use is the largest single factor associated with new cases of HIV infection in Miami Dade (William Stern et al., 2001).

Researchers have found that adolescents who become involved with the criminal justice system are frequently chronic users of alcohol and marijuana (Juvenile Assessment Center, 2004). Therefore, these adolescents are at high risk of engaging in sexual risk taking behaviors and experiencing health consequences from that behavior. There have been several studies that have examined the relationship between substance use and the engagement in sexual risk behaviors among detained adolescents (Canterbury, Mcgarvery, Sheldon_Kelley \& Reams, 1995; Kingree \& Phan, 1995, Teplin, Mericle, McClelland, \& Abrahan, 2003; Lezcano \& Vazquez, 2006). Some of those researchers have found that substance use may have an effect in the judgment of the adolescents, leading them to sexual risk taking (Castrucci \& Martin, 2002).

Cottler, Heltzer, and Tipp's (1990) seminal study on the sexual risk behaviors of 3,004 adults living out in the community and 494 living in institutions established a clear relationship between substance use and the sexual risk behaviors of the interviewed individuals. The result of that study showed that promiscuous behavior among men and women was associated with substance use behavior that included drug use such as cocaine (Cottler et al., 1990). For example, promiscuous women (defined as having sexual intercourse with more than 10 partners in 1 year) were 35 times more likely to report a pattern of substance use than women who were not promiscuous. Promiscuous men were six times more likely than their non-promiscuous peers to report a substance use pattern, including abuse of pills, marijuana, cocaine, and heroin (Cottler et al.) 
Although that was one of the first studies carried out on the general population, and the sample size was large enough to allow for the testing of interactions among many factors, the findings of Cottler and associates' study call for cautious generalization to adolescent detainees and even more caution to minority adolescent detainees because of poor generalizability to this population.

The Cottler et al. (1990) study provided an expectation of an association between risky sexual behavior and substance use, but left unanswered the question of whether similar associations would be observed within the subgroup of minority adolescent detainees in the current study. Since Cottler et al., more studies have been conducted that documented the relationship between substance use and sexual risk behavior in diverse populations, including detained adolescents (Devieux, Malow, Ergon-Perez, Samuels, Rojas et al., 2005a; Kalichman, Stein, Malow, AverHart, Devieux et al., 2002; Kingree \& Betz, 2003). The results from these studies have reinforced the findings found in the Cottler et al. study.

Kingree and Betz (2003) published one of the few studies documenting the sexual risk behavior of male adolescent detainees. They collected data on a sample of 210 African American male adolescents in which the participants responded to a structured interview with questions that asked about abuse of alcohol and marijuana and about sexual risk behaviors. Using hierarchical logistic regression they found that in the context of sexual intercourse, participants used marijuana more frequently than alcohol (45\% vs. $11 \%$ respectively). The participants' partners were also more likely to have used marijuana in the context of a sexual encounter. Kingree and Betz also found that 
marijuana rather than alcohol was highly associated with non-use of condoms; a finding similar to other studies involving the general population.

Despite their significant findings, Kingree and Betz (2003) did not control for parental approval of condom use and sexual attitude towards the use of condoms, thereby limiting the study's contribution towards understanding the relationship between substance use and sexual risk behavior among African American juvenile detainees. Researchers such as Brook et al. (2004), and others have found that drug abusing adolescents with positive social bonds with peers and parents, mothers in particular, are less likely to engage in sexual risk behaviors. Another factor that calls for caution when generalizing from the Kingree and Betz (2003) study was the use of logistic regression for an interview data set. A survey regression or a probit analysis would have been more robust (Tabachnick \& Fidell, 1996). Finally, the Kingree and Betz study did not include Latino detainees, who presently comprise a significant percentage of detainees nationwide and in particular in Miami, Florida. The present study addresses the limitations of Kingree and Betz's study, particularly in focusing on the role that peer and parental approval for condom use have on decreasing sexual risk behavior in a heavily Hispanic population of detained minors.

In another study, Kingree and Phan (2001) studied marijuana use and HIV risk among adolescent offenders. Their study included 272 adolescent offenders in juvenile facilities in metropolitan Atlanta. The participants interviewed were mostly African American males (85\%) with an average age of 14.72 years. Participants were asked about their use of marijuana and their sexual history in the last 30 days. Urine specimens were collected to be tested for STD. Specifically, the study demonstrated that $53 \%$ of the 
participants reported using marijuana in the last 30 days. Twenty three percent of the participants tested positive for marijuana in their urine tests and 14\% tested positive for chlamydia or gonorrhea. That study also found that marijuana use was significantly associated with unprotected $\operatorname{sex}(B=-2.22 \mathrm{AOR}=8.27 \mathrm{p}=0.001)$. Similar to other studies done among adolescent law offenders, generalizations from that study must be done carefully since findings may be limited to African-American and White populations. A second limitation of that study was that although the biological tests helped to confirm the participants' answers about their use of marijuana, the tests performed could not detect use beyond the previous 7 days.

In a secondary analysis of the same data set, Kingree et al. (2000) examined unprotected sex as a function of alcohol and marijuana use among adolescents. One hundred and fifty three participants were randomly selected from two detention centers in Georgia, interviewed, and stratified for gender and race. Sixty-six percent of the participants were African Americans. The researchers used three different methods in their study. The first one was the global association, which is employed to see if the total use of substances is associated with unprotected sex; the situational method (counts the occurrence of unprotected sex within a defined time period); and the event based analysis (focusing on the most recent event). They examined AIDS knowledge, and attitudes towards condoms. Results from paired $t$ tests and linear regression analysis showed that unprotected sex occurred more often for detainees with relatively negative attitudes toward condoms and greater use of marijuana (Kingree et al., 2000). Some of the limitations of the 2000 study by Kingree and colleagues are that it only focused on marijuana and alcohol and that the majority of participants were African American, 
diminishing the generalizability of these findings to Latino and White adolescent detainees. The current dissertation examines the relationship between alcohol, marijuana and other drugs such as cocaine, and the sexual risk behavior of Latino and AfricanAmerican adolescent detainees to further add to the results reported in the Kingree et al. (2000) study.

Morris et al. (1995) also studied the health risk behaviors of adolescents in correctional facilities. These researchers used a modified version of the CDC's Youth Risk Behavior Surveillance System (YRBS) to study 1801 minors in 39 correctional facilities in the U.S. The YRBS is a self administered survey that was modified to 45 questions for the purposes of their study. Questions regarding body image, sports and nutrition and school performance were eliminated and questions about HIV knowledge, drug use, and sexual behavior were added. Detailed explanations and slang were also added to improve comprehension of the survey. Furthermore, to deal with low educational levels in the sample, the questionnaires were administered by trained staff. In that study, correctional institutions were randomly selected to participate and although five declined, those institutions were from the same states where other institutions did participate.

Female youth comprised $12.2 \%$ of the sample and male youth $87.8 \%$. African American males made up most of the male group. According to that study, by age 12 a cumulative $50 \%$ of the participants had engaged in sexual intercourse and alcohol use (defined as drinking more than 20 days in their lifetime). The figures were not significantly different among males and females ( $49 \%$ and $55 \%$ respectively). That study also found that marijuana was the most used illegal drug among adolescent detainees 
with $40 \%$ using it more than 40 times. Moreover, in that study cocaine was used more frequently and at an earlier age among females ( $42 \%$ versus $30 \%$ for males). By 14 years of, age $30 \%$ of the female participants and $18.6 \%$ of the males had used cocaine (Morris, et al., 1995). Those researchers also reported that sexual activity among adolescent detainees began at the age of 12 across all the ethnicities except for Native Americans and Asians $(\mathrm{p}<0.001)$. However, that study did not examine what role substance abuse had in inhibiting the behavior of adolescents prior to their engaging in sexual behavior, including the use of condoms. As with the previous research cited above, the sample primarily involved African-American adolescents decreasing its generalizability for Latino adolescent detainees. In the current study the researcher addressed some of these racial gaps in the existent literature.

In 2005 Devieux and colleagues (Devieux et al., 2005a, 2005b) compared 81 African American to 57 Cuban American adolescent detainees in Miami Dade, Florida. The researchers drew their sample from a larger sample and utilized the modified version of the sexual risk assessment measures developed by Gibson and Young (1994) to collect retrospective data on the number of sex partners and incidents of unprotected sex during the previous 3 and 6 months. Substance use was measured by the frequency or the total number of occasions of alcohol, marijuana and other drugs used during the previous 3 and 6 months prior to their arrests.

The results of that study showed that anal sex was more prevalent among Cuban Americans during the 3 and 6 months prior to detention. Engaging in anal sex is the riskiest form of sexual behavior since, unlike vaginal sex, there is no natural lubrication. This increases the chances of micro-cuts and the presence of blood. However, there was 
no significant ethnic difference in the number of sexual partners or in the total number of vaginal or oral sex acts during the 3 and 6 months prior to their detention. Unprotected vaginal sex was more prevalent among Cuban American adolescents $(t=2.01, \mathrm{P}=0.48)$ as well as higher levels of unprotected receiving and giving oral sex. Another significant difference between the Cuban American and the African American group in the Devieux et al. (2005a) study was the use of alcohol and drugs during the 3 and 6 months prior to their detention. Ninety three percent of Cuban Americans had used alcohol compared to $67 \%$ of African Americans (Devieux et al., 2005a). The current study was undertaken to better understand how the HIV knowledge, condom use attitudes, condom use skills as well as drug use factors are related to the high incidence of risky sexual behavior among these and other detained adolescents of the NIDA funded parent study.

Similar results were found in the data from a study that used the school based Monitoring the Future (MTF) survey data, which indicated that Latino adolescents have the highest reported illicit substance use of any ethnic group in the United States after White adolescents (Wallace, Bachman, O'Malley, Schulenberg, Cooper et al., 2003). However, those study results did not directly examine the relationship between substance use and sexual risk behaviors in their study sample, which was one of the major goals of the current study. Generalization from the MTF data to adolescent detainees needs to be done with prudence since that study was done with adolescents attending schools, a group which may have different characteristics than detained adolescents.

Condom Use: Parental and Peer Approval

The relationship between parental and peer cues to action have been studied among adolescents in general. Cues to action are reminders one receives that will prompt 
him to engage in a particular behavior. Relative to engaging in behaviors connected with sex, these reminders could be in the form of incentives received from parents such as verbal messages or from literature promoting abstinence. However, that relationship has not been sufficiently studied among adolescent detainees. There are various concerns based on the risk behaviors reported by detained adolescents and one of the greatest concerns is the early age at which many of them began engaging in sexual risky behaviors. Although gender and drug use have been associated with such behaviors, other psychosocial variables such as individual, peer and parental attitudes and beliefs towards condom use have not been examined. The correlation between perceived parental approval of condom use and condom use has not been studied as much as the relationship between parent and adolescent communication and adolescent safe sex practices (DiClemente, Wingwood, Crosby, Cobb, Harrington et al., 2001). The theoretical framework that grounded this study emphasizes the importance of one's perceptions in stimulating or prompting one's health related behaviors. Therefore, in order to contribute to the literature, in this study the researcher examined participants' perceptions of parental attitudes toward the use of condoms.

One example of the research that does examine the relationships between parentadolescent communication and sexual risk behavior was conducted by DiClemente and colleagues (2001). In that study, the researchers administered structured face-to-face interviews and then two follow-up telephone interviews to 552 sexually active African Americans in low income neighborhoods. In their sample, DiClemente et al. found that the communication about sexual activity between parents and adolescents was associated 
with adolescents' use of contraceptives in the 6 months [AOR $=1.7]$ previous to the interview.

The results of that study are similar to others that indicated that parents' open communications with adolescents could reduce the adolescents' likelihood of engaging in sexual risk behaviors. The sample of that study was composed solely of female African American adolescents and its results therefore may not be generalizable to adolescent males and to other racial/ethnic groups. However, the findings of DiClemente and colleagues, (2001) further elucidate the critical role that a parent plays in helping adolescents avoid sexual risk behaviors. In order to address that important variable, the researcher of this study examined male and female adolescents' perceived parental approval of condom use. Given that detained adolescents may well have a ruptured communication with their parents, many of them may not have had open conversations with them. However, based on their shared experiences with their parents and knowledge of their parents' morals and beliefs, in this study it was assumed that the adolescents did have a sense about their parents' approval or support for condom use.

Similar studies that have focused on adolescent sexual behaviors have focused on adolescents' ability to refuse unwanted sex (Sinoean, DiClemente, Wingood, Crosby, Cobb et al., 2002). Such studies have also shown that when adolescents spoke frequently with their parents about sexual issues, they were more likely to consistently refuse unwanted sex. In one study (Sinoean et al., 2002) safer sex was measured using a scale in which the questions focused on the adolescents' ability to negotiate the use of condoms during sex with their partners. Although that study was done exclusively with African American adolescents from at-risk neighborhoods, the results should be further 
investigated using other populations of racial/ethnic minority adolescents (such as those who are detained) who may present many of the same characteristics as these at-risk adolescents.

The perceived parental approval to engage in safe sex (use of condoms) was measured in that study and adolescents with higher perceived parental approval were found to be more likely than other adolescents to refuse unwanted sex (Sinoean et al., 2002). Although refusal of unwanted sex (unprotected sex) can be attributed to many factors such as fear of pregnancy or of acquiring an STD, or the perception that the partner would not want to wear a condom, it is important to continue exploring factors that affect adolescents' sexual behavior. Further studies will help develop better interventions and assist practitioners in teaching the skill of refusing unprotected sex (Sinoean et al., 2002). Research such as the present study might ultimately help inform intervention programs that assist adolescents in becoming more knowledgeable about the different risks involved in negotiating safer sex and help them avoid risky sexual behaviors.

It is important to learn about parental approval of condom use because studies have shown that adolescents who have infrequent communication and know less about their parents' beliefs about condom use were almost 4 times less likely to communicate with their partners about condom use. Furthermore, these adolescents were $50 \%$ less likely to report condom use during their most recent sexual encounters than their peers with frequent parental communication (Crosby, DiClemente, Wingood, Cobb, Harrington et al., 2002). The results from the Devieux et al. 2005 study mentioned earlier further indicated difference between unprotected vaginal sex and oral sex among adolescent 
detainees. Adolescents were less likely to use protection when engaging in oral sex. In addition to knowledge about STD transmission and condom use, family mores and values have been shown to play a role in the behaviors of adolescents. In a study done by Grumbaum, Kann, Kinchen, Ross, Gowda et al. (2000), African American adolescents were found more likely than other adolescents to use condoms. These findings could be related to their beliefs about condom use and their perceived approval from parents and peers to use protection. Therefore, studies focusing on adolescent sexual risk behaviors should include family and peer variables. Once again, the results of that study should be cautiously generalized since it was a convenience sample and only African American participants were studied.

Crosby et al. (2002) studied a sample of 522 African American adolescents. Participants were recruited from two adolescent clinics and four health department clinics in high risk neighborhood characterized with high levels of unemployment, substance abuse, teen pregnancy and STD. Data were collected using a self administered questionnaire and followed up with a face-to-face interview. In that study, participants who had significantly lower mean scores on the assessed measure of communication with their parents also had lower mean scores on family approval of condom use. Although the results of that study have to be carefully generalized to other groups of adolescents, it is consistent with results from other studies that suggest that parent-adolescent discussions of modeling for sex related issues and modeling for sexual communication can be a really important future component of prevention programs (Crosby et al., 2002). 


\section{Adolescents' Attitudes Toward the use of Condoms}

In a recent study (Lescano, Vazquez, Brown, Litvin, et. al, 2006) that examined condom use and condom attitudes among adolescents recruited from three primary health care clinics, it was reported that there was no difference between the number of incidents of unprotected sex between adolescents with casual and main partners. HIV negative participants were interviewed $(\mathrm{N}=1316)$ using an audio computerized self interview (ACASI). In that study adolescents' attitudes towards condoms were significantly related to their condom use with main partners but were not related to their condom use with casual partners. Condom use with main partners (i.e., boyfriend, lover, and girlfriend) was significantly related to having a favorable or unfavorable expectation. Not unexpectedly, participants who perceived negative attitudes towards condoms from their main partners were less likely to use condoms (Lescano, Vazquez, Brown, Litvin, et. al, 2006). That study provides important insight in the relationship between condom attitudes and condom use. Similar to other studies, there were more African American participants (49\%) in that study than any other racial/ethnic category. Also, it is important to note that the study included a large percentage of females. Fifty percent of the sample was composed of females and although representative of many cities in the U.S., (i.e., Miami, Florida; Providence, Rhode Island; and Atlanta, Georgia), therefore, results of that study may have may have limited application for detained adolescents since its sample was community based.

Robertson, Stein, \& Baird-Thomas (2006), interviewed 523 incarcerated adolescents, most of whom were male ( $n=328$ males and $n=195$ females). In that study 10-17 year old participants volunteered to provide information about their alcohol, drug 
use, and sexual behavior. Ninety percent were African Americans, 9\% White and 1\% of other race/ethnicities. They found that positive condom use attitude (along with other variables such as knowledge, peer influence, risk perception, and condom use selfefficacy) was associated with condom use among male and females in their study. However, male condom use was strongly influenced by condom use attitudes. Although most of the participants in that study were of African descent, and the results have to be cautiously generalized to detained adolescents in Miami, Florida, it is possible that condom use attitude help predict condom use in the current study.

\section{HIV Knowledge and Condom Use}

Other authors (DiClemente, Lanier, Horan, \& Lodico, 1991) have compared AIDS knowledge and attitudes toward sexual risk behaviors between detained and public school adolescents. Because levels of risky sexual behaviors are higher among delinquent adolescents than among the general population, it is necessity to learn more about why there is such difference. Other researchers have found conflicting results when examining HIV knowledge and condom use among detained adolescents. In a study done by Robertson, Stein, and Baird-Thomas (2006), they interviewed 523 incarcerated adolescent offenders. Ninety percent of the participants were African Americans and more than half of them were males. This study examined HIV knowledge by using an 11question test. Although 95\% answered the questions correctly, knowledge of HIV/AIDS was not significantly associated with condom use. Females who reported high knowledge in that study also reported lower condom use (Robertson et al., 2006). Studying detained and incarcerated adolescents is important for developing more specific research based prevention interventions and for the better allocation of funding. The current study not 
only re-examines the association between HIV knowledge and condom use but also includes other understudied variables among the detained adolescent population.

Diclemente and colleagues (1991) studied a sample of 113 incarcerated youth and 802 public school students. Public school participants were recruited from nine high schools in San Francisco. All participants completed a CDC self report survey, following the same protocol. The incarcerated youth were much less knowledgeable about how to reduce their risk of acquiring HIV or other STD. There was a great disparity between the knowledge levels of the two groups; $75 \%$ of the incarcerated youth identified condoms as reducing the risk of STD transmission, while $85 \%$ of the high school students did so. Furthermore, incarcerated adolescents were less likely (56\% vs. $62 \%)$ to know that sexual abstinence and not having a partner who uses IV drugs reduce the risk of acquiring HIV. Additionally, incarcerated adolescents were more likely to perceive themselves at risk of acquiring an STD than their high school counterparts (DiClemente et al., 1991).

Although the DiClemente et al. (1991) study was done with incarcerated adolescents who may have committed more serious delinquent acts than the detained adolescents assessed in this study, there are various similarities between adolescents who are incarcerated and those who are detainees. Incarcerated adolescents have been found more likely to be sexually active and to have initiated sex at an earlier age than high school students. The incarcerated group of adolescents in the DiClemente et al. study also used condoms more inconsistently than their counterparts.

Gender and Sexual Risk Behavior

Studies focusing on gender and risky sexual behaviors among adolescent detainees differ in their results. Many researchers have documented a higher rate of 
sexual risky behaviors among male adolescents, while others have not found marked differences. One example is a study done in a Chicago adolescent juvenile detention center. In that study $90 \%$ of male detained adolescents were sexually active and $60.8 \%$ had sex with more than one partner in the 3 months previous to being interviewed versus $17.10 \%$ of female adolescents who did so (Teplin, Mericle, McClelland, \& Abram, 2003). Contrary to this, other studies have found adolescent females to have a higher involvement on risky sexual behaviors (Lederman, Dakof, Larrea, \& Hua, 2004; Markham, Tortolero, Escobar-Chavez, Parcel, Harris et al., 2003). The literature is not conclusive regarding this behavior since there have also been other studies that found no difference between incarcerated adolescent males and females level of engagement in risky sexual behavior (Morris et al., 1995).

Lescano, Vazquez, Brown et al. (2006) also reported that males were more likely to report casual sex and although they were more likely to use condoms with casual sex partners, they also had more sexual encounters with casual partners, hence their level of risk of acquiring an STD or facing other unprotected sex consequences was similar to participants who reported a main partner. Robertson, Stein, \& Baird-Thomas (2006), conducted a study that interviewed 523 incarcerated adolescent offenders. They also reported that being male predicted condom use. Their study also found that although female adolescents reported greater knowledge and higher perceived risk of infection, they also reported less peer influence to use condoms and less condom use (Robertson et al., 2006). The researchers proposed that it may be problematic for females to control condom use due to the power imbalance in their relationships with males. Typically, females may not be able to negotiate condom use with their male partners (Robertson et 
al., 2006). Other studies, such as that conducted by Teplin et al., (2003), have also found no differences between males' and females' sexual risk behaviors.

The following paragraphs will synthesize the review of the literature and survey the purpose of the current study. The current national and countywide epidemiological HIV/AIDS public health data calls for the further investigation of risky sexual behaviors among adolescents. Furthermore, 2002 data from the CDC showed that Latinos are the second largest group reporting HIV/AIDS in Miami Dade County. Hence, there is a tremendous need for more representation of Latinos in behavioral research studies such as the current one. According to the different studies cited in this literature review, the morbidity associated with the use of alcohol and other drugs are also associated to unprotected sex. This health problem seems to be larger among adolescents' delinquents and the related subgroup of detained adolescents.

The Kingree and Betz (2003) study among others supports that marijuana use is significantly associated with not using condoms. The purpose of the present study was to examine the associations between illicit drug use, attitudes towards condom use, and condom use behavior. It was hypothesized that, higher condom use would be reported among the illicit drug using adolescents who have more positive attitudes towards condom use. Similar hypotheses have been tested by other studies in which most of the participants were African Americans. In the current study a greater representation of Latinos will add to this literature. Furthermore, previous studies on Latinos (Devieux et al., 2005) reported that alcohol use among Latinos was higher than among African Americans. The inclusion of alcohol use in the current study is an important addition that 
permits further exploration of the associations between substance use, condom use attitudes, and behaviors among the Latino adolescent detainees.

Other studies' results have associated the use of condoms with participants' perception of their main partners' attitudes of condom use (Lescano, Vasquez, Brown et al., 2006). It has been documented by other studies that positive attitudes towards condom use are associated with condom use (Robertson, Stein \& Baird-Thomas, 2006). The current study examined if participants' condom use was positively influenced by their peers. In the current study it was explicitly hypothesized that condom use behavior was influenced by participants' perception of their peers.

According to the DiClemente et al. (2001) study, parents' open communication with adolescents was associated with lower likelihood of engaging in risky sexual behaviors. In the current study, adolescent detainees may not have had a good communication with their parents, but these adolescents may have had some perception of their parents' approval of their condom use. Therefore, in the current study, adolescents reported their perceived approval of condom use and those with higher perceived approval are expected to report higher odds of using condoms.

The contrasting findings about HIV knowledge and risky sexual behaviors, as well as the difference between detained female and male adolescent risky sexual behavior patterns reported in previous research indicates a need of further research on risky sexual behaviors among adolescent detainees. Would knowledge of HIV/AIDS prevention be significantly associated with condom use in the current study? Additionally, we may find differences between males and females in the current study. 
Studying condom use is critical in sexual behavior studies and STD/HIV prevention among adolescents since unprotected sex is the primary source of infection in Miami Dade (Williams, Stern et al., 2000). The prevalence of STDs among detainees seems to be higher than among other identifiable adolescent groups (CDC, 2004). Since most epidemiological studies are conducted a-theoretically, it was important to frame the current study with the context of a well established theoretical model of health behavior. The HBM was used to provide a theoretical framework for generating hypotheses concerning the relationships examined in the current study.

\section{Research Questions}

In order to address the gaps highlighted in the current's study's literature review, such as more inclusion of Latinos, examine condom use skills, condom use attitudes and race/ethnicity, the following research questions will be answered:

1. Is the (a) level of alcohol use, (b) level of other illicit drug use, and (c) the history of sexually transmitted diseases related to the level of detained adolescents' condom use while controlling for gender and race/ethnicity?

2. Is the (a) level of sexual risk behavior attitudes, (b) level of HIV knowledge, (c) gender, (d) level of condom use attitudes, and (e) the level of skills to use a condom related to the level of detained adolescents' condom use while controlling for gender and race/ethnicity?

3. Is the (a) level of peer approval of condom use, (b) parental approval of condom use, (c) alcohol use, and (d) level of other illicit drug use related to the level of detained adolescents' condom use while controlling for gender and race/ethnicity? 
Theories and Models Used to Understand Adolescents Sexual Behaviors

It is evident from the existent literature that there is a need to learn more about the factors related to risky sexual behaviors among detained adolescents. Various theories have been used to understand factors that explain how adolescents engage in risky sexual behaviors. In the following paragraphs, brief descriptions are provided of several theoretical approaches that have been used to study risky sexual behaviors among adolescents. The Health Belief Model (HBM) is described in detail, as it is the model used to guide this study.

The HBM was selected to guide this study after reviewing other health models that have been used in examining sexual risk behaviors among adolescents. One of the models considered was the ecological model. This model has been used in different studies that have identified and measured the relative influence of factors such as family and social interactions found to be associated with risky sexual behaviors and with STD acquisition (McLeroy, Bilbeau, Steckler, \& Glanz, 1988). However, in the current study the focus was not to measure social interactions but rather the participants' perceived parental and peer approval of condom use. Hence, the ecological model was not found to be appropriate.

Another theoretical approach used to study risky sexual behavior has been social cognitive theory (Bandura, 1994; National Cancer Institute, 2005). Social cognitive theory posits that behaviors are primarily caused by expectations. This theory has been developed and supported by Bandura who stated that individuals will base their behaviors on the expectancies they pick up from cues in their environment relating to the potential consequences of their actions and their own ability to perform the behavior needed to 
produce desired effects - their self efficacy (Rosenstock, Strecher, \& Becker, 1988). One group of researchers who have used this theory reported findings that support the relationship among adolescents' attitudes, beliefs, intention, and engagement in sexual risk behaviors were Pantin, Prado, Swartchz, and Sullivan (2005).

\section{Health Belief Model}

While there is much similarity between the social cognitive theory and the Health Belief Model (HBM), and both theoretical models have been commonly used in an attempt to understand and explain changes in adolescent behaviors, the HBM has been used more extensively by researchers examining the sexual risky behaviors of adolescents (Bryan, Rocheleau, Robbins, \& Hutchison, 2005; DiClemente \& Peterson, 1994). The wide use of HBM in the exploration of public health issues such as substance abuse and sexual risk behaviors among adolescents (Fishbein, Triandis, Kanfer, Becker, Middlestadt et al., 1991; Kolbe, 1987; Rosenstock, 1974) resulted in the selection of this model as the most appropriate to provide a framework that would help select the behaviors considered in this study.

The HBM was created by Rosenstock (1974) and it posits the idea that people will engage in health related behaviors if they: (a) perceive a threat and (b) believe that by taking an action, they will prevent a negative health condition (e.g., engaging in safer sexual behavior to prevent HIV infection). When people are exposed to what Rosenstock came to call cues to action or prompts to action such as a national AIDS prevention day, they may be stimulated to engage in safer sexual behaviors.

According to Rosenstock (1974), the perceived threat may be thought of as having two parts: (a) the perceived susceptibility, which is the subjective risk of 
contracting an illness and (b) the perceived severity, which is defined as feelings regarding the seriousness of the disease. The seriousness of the disease is thus subjectively defined. Some examples of factors about which individuals hold perceptions of severity are loss of bio-physical abilities (e.g., the ability to bear children) and negative social consequences (e.g., stigma due to HIV diagnosis).

The personal characteristics of the participants in this study can be divided into: demographic (such as race/ethnicity, age, education, condom use skills, sexual risk attitudes, and condom use attitudes), behavioral (drug use), and physical health (history of STD). These personal characteristics variables are important due to the fact that they have been found to play a role in perceived threat and severity of illness; hence, having an effect on individuals engaging in a health behavior (Rosenstock, 1974; Rosenstock, Strecher, \& Marshall, 1994). Furthermore, an individual's HIV knowledge and perception of parental and peer approval to use condoms may vary depending on those characteristics.

The HBM grew out of the major conditioning theory developed in the 1920s by Ivan Pavlov (Rosenstock, 1974). Pavlov's conditioning theory posited that a person's behavior was physiologically rather than cognitively driven. Actions are unconsciously taken in physical expectation of getting a reward. These two theories combined in the creation of the HBM model consider individuals' cognitive abilities and that is why today the HBM contains Rosenstock's beliefs components.

One prominent adjustment to the nascent form of the HBM was the addition of the prompt to action concept which posits that reinforcement by reminders and encouragement will help people take actions to prevent a negative health effect 
(Rosenstock, 1974). The cues to engage in certain behavior could be from various sources such as receiving a postcard in the mail that it is time for a yearly physical exam or glancing at a billboard for a few seconds while driving. The HBM has been helpful to explain the findings of a study of community vaccination before a flu epidemic.

Although the sample for that study was small, it is worth noting that it found that people who believed they were susceptible to the influenza and that the disease had serious consequences were more likely to participate in the vaccination campaign (Rosenstock, 1974).

In the current study, it was hypothesized that perceived peer and parental approval for condom use would provide stimulus for participants' awareness and encourage them to use a condom when having sex. Additionally, these hypotheses were based on the Fishein and Guinan (1996) finding that adolescents who perceived that (a) others are also changing their behavior; and (b) those with whom they interact closely support the behavior were more likely to change their own behavior. In the current study, knowledge of how HIV is acquired and perceived vulnerability to HIV/AIDS was used as a proxy of perceived risk. Condom use attitudes, condom use skills and perceived support to use condoms from parents and peers are analyzed independently. In the current study, the researcher did not group the factors following the more general application of the HBM.

Health behavior change has been examined with various models, but in the last decade the ecological model, the HBM, and the social cognitive model were most often used in studies of risky sexual behavior. The latter two models have a commonality: they hypothesize individuals will behave based on certain expectations. A similarity between the HBM and the social cognitive model is their speculation that individuals will be 
influenced to act by an environmental stimulus. The current study's focus on the individual's characteristics and social cues lends itself to be guided by the HBM, which relies heavily on the cognitive abilities of the individual to make health related decisions such as condom use.

Figure 1, which follows in the next page, is a schematic representation of the concepts that constitute the health belief model as it is used in the current study. Although the HBM does not include the variables of race/ethnicity and gender to guide and predict health behaviors, the preliminary results suggested that these variables may moderate the associations expected to be found on the basis of the HBM framework. Therefore, race/ethnicity and gender were included as control variables in the current study's models that evaluated the research hypotheses. Listed within each element of the HBM are the variables used to operationalize the model in this study.

The HBM model provides the conceptual foundation for posing a set of research questions that the literature review here indicates have yet to be adequately addressed. While there are limitations (discussed more fully in Chapter V) in using an existing data source to examine the putative relationships set out in these questions, there is a critical need (as argued in Chapter I), to better understand what influences condom use practices among delinquent minority youth who exhibit high risk behaviors. Accordingly, the following research questions were addressed in this study:

1. Is detained adolescents' (a) level of alcohol use, (b) level of use of illicit drugs, and (c) history of sexually transmitted diseases related to their condom use while controlling for gender and race/ethnicity? 
2. Is the (a) level of sexual risk behavior attitudes, (b) level of HIV knowledge, (c) condom use attitudes, and (d) level of skills to use a condom related to the level of detained adolescents' condom use while controlling for gender and race/ethnicity?

3. Is detained adolescents' (a) level of peer approval of condom use, (b) level of parental approval of condom use, (c) level of alcohol use, (d) level of use of marijuana, cocaine and other drugs related to their condom use while controlling for gender and race/ethnicity?

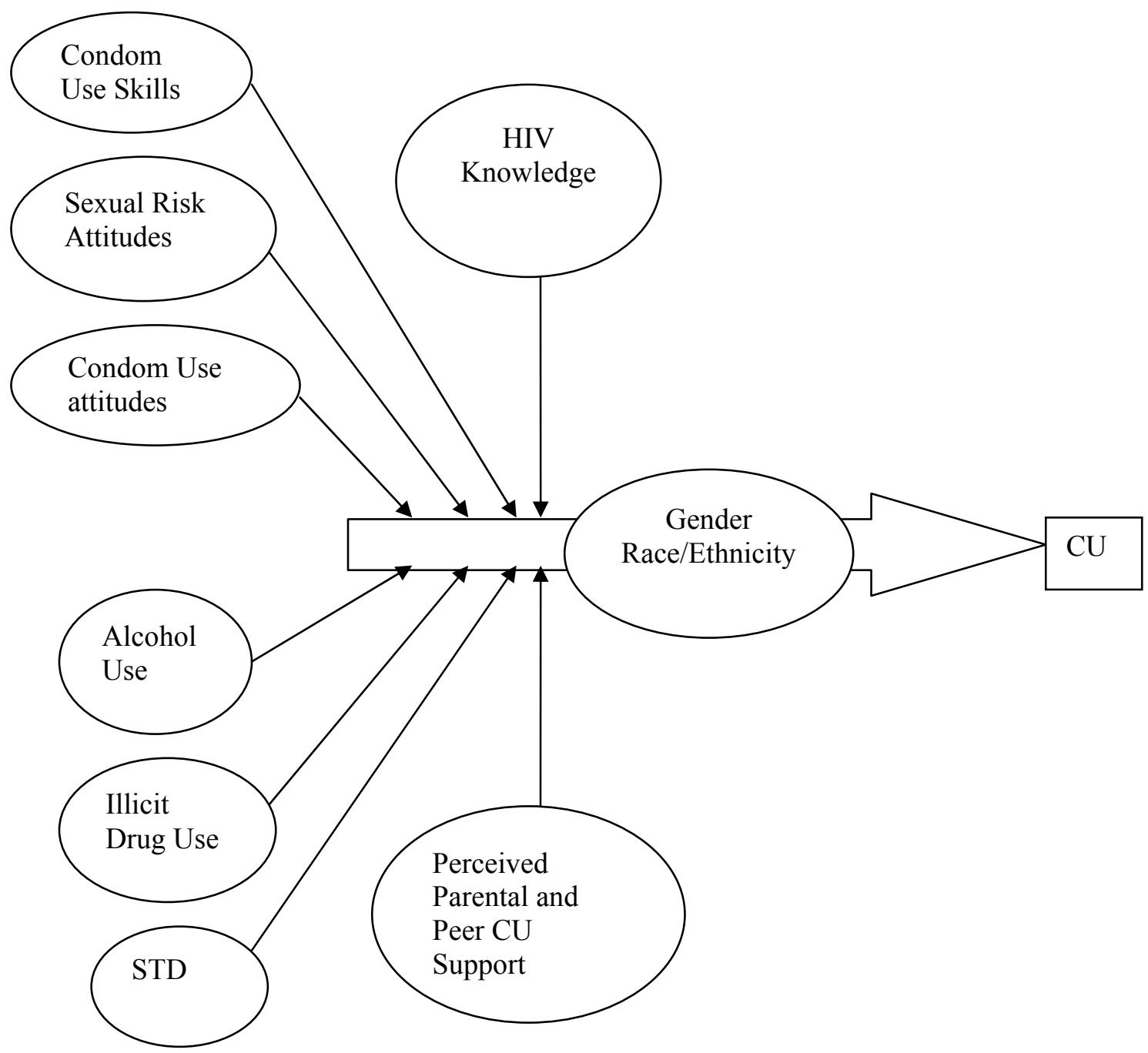

Figure 1. The health belief model as a guide to the current study. 
The variables in each Question are guided by the HBM depicted in the model in Figure 1. In this study, attitudinal and skill level factors are part of the personal characteristics construct. In Question Two, the level of HIV knowledge has been guided by the perceived threat construct in the HBM and other variables such as condom use attitudes and skills by the personal characteristics variables. In Question Three, the peer approval and parental approval elements were guided by the cues to action construct of the HBM. Although it is not clear just how cues to action influence an individual to move from the perceived vulnerability to the state mind of high threat making the action certain (Rosenstock, Strecher, \& Marshall, 1994) it is a tenet of the model that stimuli to engage in certain behavior are very important.

Learning how condom use is related to the beliefs, attitudes, and knowledge level of adolescents is imperative to creating more effective preventive programs (American Academy of Pediatrics, 2001). As Rosenstock and colleagues (Rosenstock, Strecher, \& Becker, 1988) said, the issue with changing behaviors that are long term, such as eating habits and sexual behaviors, is that people need to have an incentive to change. If people think that there is a benefit, then they will engage in the health seeking behavior. This study was based on the same proposition, focusing on using condoms during sexual activity as the healthy behavior. Guided by the HBM, this study analyzed whether a number of socio-psychological factors (some of which are risk factors), knowledge of how HIV is transmitted (perceived threat), and parental and peer approval to use condoms (cues to action) were related to detained adolescents' sexual behavior practices (condom use). 
In the next chapter, the researcher presents detailed definitions of each factor representing the HBM constructs, and the data analysis strategies used to answer the research questions. Chapter III also includes an explanation of the participants' recruitment and data collection methods used in the current study (i.e., those of the parent study). 


\section{CHAPTER III}

\section{METHODS}

This study was based on a secondary analysis of an existing data set. Therefore, a considerable part of the methods (i.e., participants' recruitment and data collection) described below was based on the parent study lead by Dr. Robert Malow. (NIDA RO1DA11875 and NIAAA RO1AA11752). The parent study was approved by the University of Miami human subject Review Board and its purpose was to evaluate the effectiveness of the HIV prevention intervention "Becoming a Responsible Teen" (BART) with 634 adolescent detainees. Therefore, pre-intervention and post-intervention data were analyzed in the parent study. BART is an 8-session sexual risk behavior prevention curriculum used primarily with African American teens between the ages of 14 and 18 in non-school settings. However, BART has also been widely used with Latino adolescents (Education Training Research Associates, 2004).

Because the main purpose of the parent study was to evaluate the effectiveness of the BART curriculum on adolescent detainees, participants were interviewed before and after participating in the BART intervention. In the parent study, well trained interviewers recruited these adolescents by approaching and building rapport with them. In the present study the researcher used baseline data collected prior to the intervention. The current study differs from the parent study in that it only focuses on the baseline data such as the condom use, baseline knowledge, condom use attitudes, and condom use skills that the adolescents had prior to participating in the intervention program. The current study was approved by the Florida International University Institutional Review Board after an expedited review of its application. 


\section{Sampling Sites}

The adolescent detainees recruited by the parent study were housed in two juvenile detention centers in Miami-Dade County, Florida. Miami-Dade is a metropolitan area with 2,253,362 people of whom 57\% are Latino (United States Census, 2000). In Miami-Dade there are 6,500 inmates residing in the county jails on any given day of whom 34\% are Latino (Miami Dade Regional Juvenile Detention Center, 2006). However, the Miami Juvenile Assessment Center (JAC) processes an unduplicated count of approximately16,333 adolescents per year (JAC, 2004). That large number of delinquent adolescents is because JAC is a processing center where all adolescents detained in Miami-Dade are sent to be evaluated by law enforcement and social services personnel. Adolescents who are arrested in Miami-Dade are processed through JAC in all matters related to their cases.

Once police take adolescents into custody, those who meet the criteria to be detained are sent to the juvenile justice building to wait for a court hearing, scheduled within 24 hours after being arrested. Criteria for detention include the type of criminal offenses (i.e., robbery, assault with arms, and drug charges) and the need to appear in court. Minors whose parents or legal guardians do not claim custody of them within the first 24 hours are detained until they can be released to a designated guardian. If they do not meet the detention criteria, the adolescents are released to a designated guardian and summoned to appear in court within 35 days of the incident. During their first 8 to 12 hours at the detention center, adolescents are evaluated for substance use and mental health. Both the parent and current study were conducted with adolescents who met the 
detention criteria. Below is a brief description of this study's detained participants and their demographic characteristics.

\section{Participants}

The participants in the current study were sexually active adolescents from Miami-Dade. These detainees were primarily low income inner city adolescents who used alcohol, marijuana, and/or crack cocaine as measured in the parent study using the Kelley Risk Behavior Scale (Malow, Devieux, Jennings, \& Lucenko, 2001). The sample for this study was composed of 455 sexually active adolescent detainees (337 males and 118 females) with a mean age of 15.6 years $(\mathrm{SD}=1.2$; range $=13-19$ years old $)$, and an average level of education of 8.68 years. As documented in Table 3, participants were mostly of racial/ethnic minorities.

\section{Recruitment}

As indicated, the recruitment and screening of participants and data collection were done by the researchers in the parent NIH funded study. Trained undergraduate and graduate level research assistants conducted the recruitment and interviewing. Research assistants approached potential participants and explained the study to each individual. Researchers explained the eligibility criteria, confidentiality issues, advantages, and risk of participating in the study to assess the adolescents' eligibility and to obtain their participation assent. All participants were compensated for their time with gift certificates to be used in local stores.

During the parent study screening for eligibility, participants were evaluated for cognitive impairment by a trained facility staff. The result of this aspect of the screening was that no participant suffered from severe mental or intellectual impairment. 
Adolescents who did not speak English fluently were excluded from the study because the questionnaires and interviews were in English only. Three potential participants who were cognitively or mentally impaired and did not provide the necessary consent forms, and two who did not complete all items in the questionnaires were also excluded from the study. Seven potential participants refused to participate or had parents who refused to consent and were not part of the sample.

\section{Assessment Measures}

All assessment instruments used in the parent study had been used with minority adolescents in previous studies and some of them were further adapted by Malow et al. (2002) to increase their cultural and age appropriateness. The interview included questions such as "When was the last time you had vaginal sex?" and "How many times have you had oral sex in the last 6 months?" For retrospective questions such as these, a calendar was shown to assist in recollection. The instruments with these and other questions were administered verbally during structured interviews that were carried out by experienced interviewers who had been trained by a Ph.D. clinical psychologist. The psychologist continuously supervised the data collection process.

Given that the current study focused on the relationship between substance use and condom use behaviors prior to any interventions, only baseline data collected in the parent study were used in it. These data were collected one week after the adolescents' admission to the juvenile detention center and after a clearance form documenting detoxification had been completed. That protocol was designed while conducting the parent study to minimize the effect of withdrawal during the phase of detoxification on 
data collection, and to maximize accurate responses for the study (Lucenko, Malow, Martinez-Sanchez, Jennings, \& al., 2003).

The data used to determine substance use, sexual risk behaviors, and history of sexually transmitted diseases were collected from the participants' self-reports during these interviews. As indicated above, to facilitate administration and increase accuracy, the interviewers used a calendar-based method. Three-month calendars were provided to help participants recall sexual risk behavior events. Participants were told to look at the calendars and provide information based on the number of days they used drugs. Each interview took approximately $1 \frac{1}{2}$ hours. To ensure the participants' understanding of each question, interviewers were trained to repeat the questions anytime a respondent showed uncertainty. Interviewers were also trained to assume a non-judgmental attitude and to establish rapport and build trust. To maximize participants' truthfulness as to substance use and sexual risk behaviors, the interviewers were trained to assure participants that all their responses were confidential. Interviews were individually conducted in a private room and participants were told that their responses were not going to be shared with the treatment staff. In order to motivate participants to respond as accurately as possible, they were told that their responses were going to be used to help other adolescents like themselves who may need substance use treatment.

$$
\text { Instruments Used }
$$

\section{Independent Variables}

Demographic variables were self reported for the parent study and were used in this study to describe the sample and to use as covariates in the appropriate analysis. Demographic data included gender, defined as male or female; age, defined as the 
number of years old the participant was; and level of education, defined as the number of years of school the participant completed. Race/ethnicity was measured as a categorical variable: White not of Hispanic origin, African American (Not of Hispanic origin), Latino (Mexican, Puerto Rican, or Cuban heritage) and other race/ethnicities (Caribbean not of Haitian origin, Haitian, Asian, or Pacific Islander). For the analyses of this study, race/ethnicity was used as a categorical variable in the data analysis. Among the independent variables used in the current study and measured by the parent study were the following:

Substance use. Substance use was measured using the alcohol and drug use variable in a modified version of the Kelly Sex Risk Survey, adapted by Malow et al. (2001). Participants answered questions about the frequency use of different drugs in the last 6 months (alcohol, marijuana, cocaine, tobacco, inhalants, and other drugs); date of last use (month and year); and the method of use of the substances mentioned above. The Cronbach $\alpha$ for this scale was .72 and when used to measure the frequency of substance use with a similar sample in the parent study was .82 (Malow, 2001).

HIV knowledge. HIV risk infection knowledge was defined using a modified version of the St. Lawrence HIV risk knowledge scale (St. Lawrence, Jefferson, Alleyne, \& Brasfield, 1995). In this measure, participants considered 18 statements with true or false responses. Lower scores suggested that the participant had a low level of knowledge concerning risks associated with HIV infection. The Cronbach $\alpha$ for this scale was .64

Sexual risk attitude. Sexual attitude was measured using a 5 point Likert scale with responses ranging from "extremely unimportant" to "extremely important." This sexual attitude scale was adapted from Jemmot, Jemmott and Fong (2000). The scale also 
included other questions that used a range from "disapprove strongly" to "approve strongly." The Cronbach $\alpha$ for this scale was .72 . When the scale was used with a sample consisting of only Cuban and African American juvenile delinquents only, the results were .72 (Malow et al., 2001).

Condom use attitudes. Personal condom attitude was measured using a 20 statement Likert scale ranging from "disagrees strongly" to "agree strongly" for some of the questions and a 4 point Likert scale ranging from "very bad idea" to "a good idea" for other questions. Higher scores on this scale suggest that the participant has a positive attitude towards condoms. The Cronbach $\alpha$ for this scale was .72 .

Condom use skills. Condom use skills were measured by rating the participant's ability to properly perform nine steps that described how to place a condom on a penis model (Sohler, Colson, Meyer-Bahlburg, \& Susser, 2000). Steps in the scale included steps such as, "Check the expiration date on the condom package" and "State that immediately after ejaculation, one should hold the condom at the base and withdraw." Participants were rated for successful completion of items or steps required to place a condom correctly on a penis model. The scores reflected the total number of correct steps (ranging from 1-9). The Cronbach $\alpha$ for this scale was .72.

Perceived condom use approval from parents and peers. Approval perceived from parents and peers to use condoms when having sex was measured using the Sexual Attitude Scale, (Jemmott et al., 2000 ) which asks about approval for the use of condoms, and how important is that approval for each participant. This scale uses a Likert scale from 1 to 5 ranging from "disapprove strongly" to "approve strongly." This scale also asked for the level of satisfaction with the perceived approval with a scale ranging from 
"very satisfied" to "very dissatisfied"(Jemmott et al., 2000). The Cronbach $\alpha$ for this scale was .73.

Sexually transmitted diseases. Participants were asked how many times they have ever been diagnosed with an STD. In the parent study, sexually transmitted diseases were measured by the number of STD participants had ever been diagnosed with in their lifetime. In the current study, the STDs variable was transformed from a continuous variable $(0,1,2,3$, or more) into a dichotomous variable (yes/no) in order to use it as a categorical variable in the logistic regression.

\section{Dependent Variables}

Risky sexual behavior was the dependent variable and was indicated as a negative response for risk (i.e. no condom use $=0$; condom use $=1$ ) during a sexual encounter. Risky sexual behavior was evaluated separately for three general types of sexual activity: 1) vaginal sex; 2) oral sex; and 3) anal sex. Condom use was dichotomized using an event/trial specification. For each type of sexual encounter over the six months prior to the baseline interview, the number of times participants used condoms was calculated as the number of times participants reported using condoms (event) divided by the total number of sexual encounters (trials).

Use of condoms was measured using the Kelly Sex Risk Survey scale (Gibson \& Young, 1994) that measures how many times participants had engaged in sexual intercourse (before their detention) and their use of condoms for anal, oral, and vaginal sex during the past 6 months. Risky sexual behavior was indicated as a negative response for risk (i.e., no condom use=0; condom use=1). The Kelly Sex Risk Survey was adapted by Malow et al. (2001) was used to evaluate adolescents' risky sexual behavior and 
frequency of substance use. This scale includes 3 questions about how many times participants had engaged in sexual intercourse previous to their detention.

\section{Data Analysis Strategies}

In preparation for conducting analyses all scales were checked for normality and homogeneity of variance. Statistical transformations were not necessary since the statistical procedure to be used, more fully described below, is robust to these concerns. (Tabachnick \& Fidell, 1996; Pampel, 2000). Sample means, standard deviations, and frequencies were calculated during preliminary analysis for descriptive purposes. Table 2 describes these variables' measures and the statistical tests that were used to find the relationship between sexual risk behaviors and STD, condom use skills, and sexual risk knowledge (as measured by the HIV knowledge scale). After preliminary analysis, the single outlier (in the number of times participant have had sexual relations) was winsorized. The distribution was winsorized by taking the highest value at the $99^{\text {th }}$ percentile and equating all responses above this value to one plus the value at the $99^{\text {th }}$ percentile of the distribution. The adjustment was done in order to reduce the impact of extreme scores (Tabachnick \& Fidell, 1996). During preliminary analysis, it was observed that the number of STD was very small (only $7.5 \%$ of the participants reported having an STD). Therefore, due to difficulty with the planned multivariate analysis (e.g., large standard errors) this variable was dropped from the final analysis as recommended by Tabachnick and Fidell.

In order to assess missing data, the pattern and number of missing values in the data were examined. There were much less than $0.5 \%$ missing values, therefore, the researcher did not analyze the data by repeating the analyses with and without the 
missing data or by using imputation to deal with the missing data (SPSS, 2003;

Tabachnick \& Fidell, 1996). In the first regression and the third regression examining anal sex (equations 1c, and 3c) the use of illicit drugs was dropped from the equation. That variable was eliminated because there was a significant correlation between condom use and use of illicit drugs (101) which caused a large standard error. During preliminary analysis, it was also noted that very few participants have had anal sex and that most of them have used condoms (Pearson's correlation=.912). During preliminary analysis, it was also noted that very few participants reported anal sex and nearly all reported condom use $(\underline{r}=.912)$. Further discussions of these decisions are provided in Chapter V. In order to use logistic regression to evaluate the research questions, condom use was dichotomized using an event/trial transformation. For each type of sexual encounter (vaginal, anal, oral) over the six months prior to interview, the number of times participants used condoms was calculated as the ratio of the number of times participants reported using condoms (event) divided by the total number of sexual encounters (trials). Gender was also dichotomized (female $=1$, male $=0$ ) and race/ethnicity was recoded into four groups ( $1=$ White, $2=$ African Americans, $3=$ Latinos and $4=$ Others $)$. The racial/ethnic group "Others" was composed of adolescents from Haitian, Caribbean not from Haitian descent, and Caribbean peoples. The logistic regressions in this study were run using SAS Version 9.1.

In order to analyze the first research question: Is the level of (a) alcohol use, (b) illicit drugs, and (c) history of STD related to detained adolescents' level of condom use after controlling for gender and race/ethnicity? A multivariate logistic regression was performed. Predictors were simultaneously added to the statistical model in SAS based 
on their order in each equation. However, gender and race were control variables, and they were entered first because preliminary analysis had shown correlation between these predictors and the dependent variables.

Table 2

Variable List, Measures, and Statistical Analyses

\begin{tabular}{|c|c|c|}
\hline Variable & $\begin{array}{l}\text { Levels of } \\
\text { Measure }\end{array}$ & $\begin{array}{l}\text { Statistical Analysis and Regression Equations Testing Research } \\
\text { Questions }\end{array}$ \\
\hline $\begin{array}{l}\text { Condom Use - } \\
\text { CU }\end{array}$ & Categorical & Regression Equation Testing Question \# 1 \\
\hline $\begin{array}{l}\text { Alcohol use - } \\
\text { OHUSE } \\
\text { Mariiuana }\end{array}$ & Interval & $\operatorname{nroh}(\hat{\mathrm{Y}}-1)=\Pi-\frac{\mathrm{E}^{\beta 0+\beta_{1} G+\beta_{2} \mathrm{OHUSE}+\beta_{3} H A R D D R U G+\beta_{4} S T D s+}{ }^{e}}{}$ \\
\hline $\begin{array}{l}\text { Cocaine and } \\
\text { other Drugs- } \\
\text { HARDDRUG }\end{array}$ & $\begin{array}{l}\text { Nominal- } \\
\text { Categorical }\end{array}$ & $1+\mathrm{E}^{\beta 0+\beta_{1} G+\beta_{2} O H U S E+\beta_{3} H A R D D R U G+\beta_{4} S T D s+e}$ \\
\hline Gender -G & Nominal & \\
\hline Sexually & Categorical & \\
\hline $\begin{array}{l}\text { Transmitted } \\
\text { Diseases -STD }\end{array}$ & & \\
\hline $\begin{array}{l}\text { Condom Use - } \\
\text { CU }\end{array}$ & Categorical & Regression Equation Testing Question \# 2 \\
\hline $\begin{array}{l}\text { Sexual } \\
\text { Behavior }\end{array}$ & Interval & \\
\hline $\begin{array}{l}\text { Attitudes -SBA } \\
\text { HIV } \\
\text { Knowledge- } \\
\text { HIVK }\end{array}$ & Interval & $\operatorname{prob}\left(\hat{\mathrm{Y}}_{C U}=1\right)=\prod=\frac{\mathrm{E}^{\beta 0+\beta_{1} G+\beta_{2} R A C E+\beta_{3} S B A+\beta_{4} H I V K+\beta_{5} C U A T T+\beta_{6} C U S+}{ }^{e}}{1+\mathrm{E}^{\beta 0+\beta_{1} G+\beta_{2} R A C E+\beta_{3} S B A+\beta_{4} H I V K+\beta_{5} C U A T T+\beta_{6} C U S+e}}$ \\
\hline Gender -G & Nominal & \\
\hline Condom Use & Interval & \\
\hline $\begin{array}{l}\text { Attitudes - } \\
\text { CUATT }\end{array}$ & & \\
\hline $\begin{array}{l}\text { Condom Use } \\
\text { Skills -CUS }\end{array}$ & Ordinal & \\
\hline $\begin{array}{l}\text { Condom Use - } \\
\text { CU }\end{array}$ & Categorical & Regression Equation Testing Question \# 3 \\
\hline Approval from & Interval & \\
\hline Parents -AFPE & & $\mathrm{E}^{\beta 0+\beta_{1} G+\beta_{2} R A C E \beta_{3} \text { AFPE } \beta_{3} \mathrm{OHUSE} \beta_{5} H A R D D R U G \beta_{6} \text { AFPA }^{e}}$ \\
\hline $\begin{array}{l}\text { Approval from } \\
\text { Peers -AFPA }\end{array}$ & Interval & $\left.\operatorname{prob} \hat{\mathrm{Y}}_{C U}=1\right)=\prod=\frac{\mathrm{L}}{1+\mathrm{E}^{\beta 0+\beta_{1} G+\beta_{2} \text { RACE } \beta_{3} A F P E \beta_{4} \text { OHUSE } \beta_{5} H A R D D R U G A F P A e}}$ \\
\hline $\begin{array}{l}\text { Alcohol use - } \\
\text { OHUSE }\end{array}$ & Interval & \\
\hline $\begin{array}{l}\text { Marijuana, and } \\
\text { other Drugs- } \\
\text { HARDDRUG }\end{array}$ & Categorical & \\
\hline Gender -G & Nominal & \\
\hline
\end{tabular}


A multivariate logistic regression was also used to evaluate the second and third question as shown in the next page on Table 2. Parental and peer approval were skewed (discussed later) but transformation was not done before the final analysis due to the robustness of the logistic regression. Table 2 shows the main variables and what types of statistical tests were used to determine statistical significance. The logistic regression models produced an appropriate fit to the data, as can be found in the following chapter. Chapter IV also contains more detailed and descriptive information about the variables used in the current study. 


\section{CHAPTER IV}

\section{RESULTS}

\section{Descriptive Statistics}

Sample

The sample in this study consisted of 455 participants who had been detained at two Juvenile Assessment Centers (JAC) in Miami, Florida. A summary of the sample and how it was selected from the parent study is provided in Figure 2. The mean age of participants was 15.69 years and the majority of the participants were males $(74.1 \%)$. Of the study participants, $62.0 \%$ engaged in unprotected vaginal sex at least once during the 6 months previous to the parent study.

Figure 2. Sample selection.

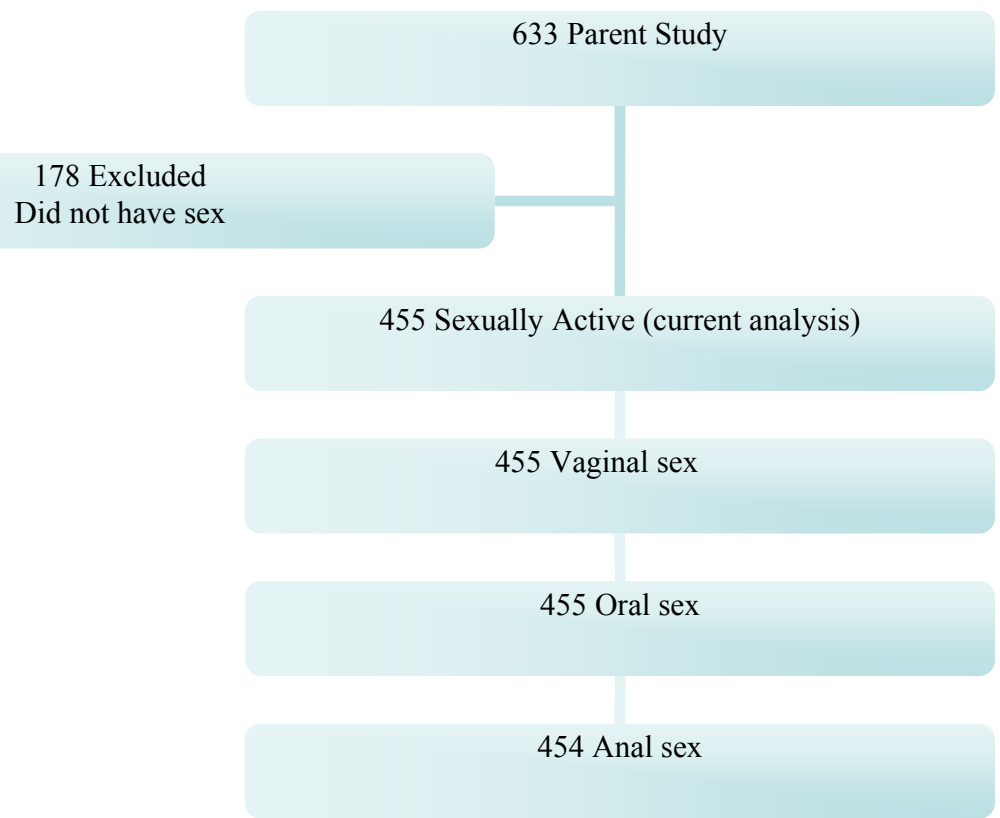


The table below provides descriptive statistics for additional variables used in the analyses specified in Chapter IV.

Table 3. Descriptive Statistics

\begin{tabular}{|c|c|c|c|c|c|}
\hline Variable & $\begin{array}{c}\text { Valid } \\
\mathrm{N}\end{array}$ & Mean $/ \%$ & SD & Min/Max & Skew \\
\hline \multicolumn{6}{|c|}{ Dependent Variables } \\
\hline CU during vaginal sex & 455 & 19.77 & 27.4 & $0-180$ & 2.71 \\
\hline CU during oral sex & 455 & 10.22 & 25.0 & $0-200$ & 4.4 \\
\hline CU during anal sex & 454 & .77 & 5.0 & $0-78$ & 11.0 \\
\hline \multicolumn{6}{|c|}{ Independent Variables } \\
\hline Alcohol use & 455 & $68.50 \%$ & 25.34 & $0-171$ & 3.41 \\
\hline Illicit Drug Use & 449 & $82.7 \%$ & 74.53 & $0-360$ & 1.05 \\
\hline Had an STD & 453 & & & & \\
\hline Yes & 34 & $7.5 \%$ & & & \\
\hline No & 321 & $92.5 \%$ & & & \\
\hline Sexual Behavior Attitudes & 455 & 4.37 & .581 & $2-5$ & -.982 \\
\hline HIV Knowledge & 455 & 13.24 & 2.80 & $4-18$ & -.447 \\
\hline Condom Use Attitudes & 455 & 3.28 & .358 & $2-5$ & -.398 \\
\hline Condom Use Skills & 455 & 4.75 & 2.18 & $0-9$ & .017 \\
\hline Peer Approval of Condom & 454 & 4.42 & .732 & $1-5$ & -1.52 \\
\hline \multicolumn{6}{|l|}{ Use } \\
\hline Disapprove Strongly & (3) & .9 & & & \\
\hline Disapprove & (9) & 2.7 & & & \\
\hline In the Middle & (21) & 6.3 & & & \\
\hline Approve & (124) & 37.0 & & & \\
\hline Approve Strongly & $(178)$ & 53.0 & & & \\
\hline Parental Approval of & 455 & 4.62 & .685 & $1-5$ & -2.75 \\
\hline \multicolumn{6}{|l|}{ Condom Use } \\
\hline Disapprove Strongly & (4) & 1.2 & & & \\
\hline Disapprove & (3) & .9 & & & \\
\hline In the Middle & (94) & 28.0 & & & \\
\hline Approve Strongly & $(235)$ & 69.9 & & & \\
\hline \multicolumn{6}{|c|}{ Control Variables } \\
\hline Gender & 445 & & & & \\
\hline Male & $(337)$ & $74.1 \%$ & & & \\
\hline Female & $(118)$ & $25.9 \%$ & & & \\
\hline Race/Ethnicity & 445 & & & & \\
\hline Latinos & $(114)$ & $25.1 \%$ & & & \\
\hline White & $(51)$ & $11.2 \%$ & & & \\
\hline African Americans & $(161)$ & $35.4 \%$ & & & \\
\hline Others & (129) & $28.4 \%$ & & & \\
\hline
\end{tabular}


The results in Table 3 denote a frequency measure of alcohol use indicated by the count of times alcohol was used in the last 6 months prior to detention. The count was then divided by the number of days in the period. The median number of drinks recoded was two. The distribution for alcohol use was skewed (skewness 3.41) due to extreme values; therefore, the distribution was winsorized by taking the highest value at the $99^{\text {th }}$ percentile and equating all responses above this value to one plus the value at the $99^{\text {th }}$ percentile of the distribution. The adjustment was done in order to reduce the impact of extreme scores (Tabachnick \& Fidell, 1996).

The use of marijuana, cocaine, and other illicit drugs was measured as the aggregation of the counts of the times each of those drugs were used during the 6 months prior to enrollment in the parent study. The aggregation was made necessary by the low percentage of use of illicit drugs other than marijuana. Similar to the distribution of alcohol use, the distribution of illicit drug was extremely broad with many cells with a count of zero $(19.42 \%)$, Therefore, this variable was dichotomized (yes $>=1$ and no $=0$ ). As documented in Table 3, more participants used illicit drugs than alcohol (80.58\% vs. $68.5 \%)$.

The number of participants who had been diagnosed with an STD was particularly low. During preliminary analysis, following guidelines from Tabachnick and Fidell (1966), a decision was made to exclude STD from the final analysis in order to avoid misinterpretations due to low cell numbers (e.g., large standard errors for the parameter estimates were observed). As seen on Table 3, there were only a small number of adolescent participants diagnosed with STD (7.5\%). It should be noted that in the current study the number of males diagnosed with STD was almost three times more than the 
number of diagnosed females. This finding could have been because males composed most of the sample. There were approximately 3 times more adolescent males than adolescent females in this study.

Peer approval to use condoms had a non-normal distribution since, as shown in Table 3, 53.0\% of peers and parents approving or strongly approving (possible values: disapprove strongly, disapprove, in the middle, approve, approve strongly). Similarly, more than half of the participants stated that their parents approved or strongly approved the use of condoms, which contributed to the non-normal distribution of this variable. Condom use attitudes had a non-normal distribution since most participants had a highly positive attitude towards condom use (please see Table 3). The distribution of sexual attitudes was also found to deviate from normality assumptions. Since the majority of participants had substantial knowledge of HIV (high scores in the scale), the result was a non-normal distribution with a mean of 13.24 as seen on Table 3. As noted above, logistic regression does not assume a normal distribution of the variables, and thus these were not transformed (Tabachnick \& Fidell, 1996). See Figure Table 3 for detailed information about the distribution of all the variables.

\section{Controlling For Race/Ethnicity and Gender}

Results from preliminary analysis of variance (ANOVA) of race/ethnicity and sexual risk behavior, showed a statistically significant effect of race/ethnicity on the levels of sexual risk behavior- oral sex $\mathrm{F}_{(3-451)}=15.99, p<.001$. A similar effect was seen for anal sex, $\mathrm{F}_{(3-450)}=6.320, p=>.001$. Similarly it was found that gender indicated a statistically significant difference between men and women for sexual risk behavior during anal sex $\mathrm{F}_{(2-452)}=6.84, p=.009$. 
Binary logistic regression analyses were used for the analyses addressing the research questions because this is an appropriate regression approach in circumstances where there is a binary dependent variable. Logistic regression offers the added advantage that parameter estimates are robust in cases where the distributions of the independent variables violate the usual assumption of normal distribution (Pampel, 2000).

\section{Logistic Regression Analysis: Fitting the Models}

In this section the interest is in modeling the effect of independent variable on the odds of condom use. The exponentiated $\left(\mathrm{e}^{\beta}\right)$ value for a parameter estimate provides the $\log$ odds ratio. The odds ratio expresses a change $( \pm)$ in the odds of condom use associated with a unit increase in the value of a covariate adjusted all other effects in the model. When odds are expressed in probabilities the formula used for the conversions was the following: $\frac{\mathrm{E}^{a+\beta x}}{1+\mathrm{E}^{a+\beta x}}=\frac{O D D S}{1+O D D S}$ (Pampel, 2000, p.16). In addition, due to the three types of sexual activity (vaginal, oral, and anal sex), multiple statistical tests were conducted for each of the research hypotheses. To avoid inflating the Type I error of rejecting the null hypothesis, a Bonferroni correction was made. For each research question the planned probability for rejecting the null hypothesis was $\alpha=0.05$. Accordingly, the adjusted probability for rejecting the null hypothesis was $\alpha=0.05 / 3=$ .017. When evaluating how well a planned model actually fits the data the Akaike Information Criterion (AIC) goodness of fit test (Singer \& Willet, 2003) is reported throughout the Results chapter. 


\section{Model One}

The first research question was: Is the level of (a) alcohol use, (b) marijuana, cocaine and other drugs, related to detained adolescents' condom use while controlling for gender and race/ethnicity? The first logistic regression examined vaginal sex. The logistic regression model is expressed as:

$$
\operatorname{prob}\left(\hat{Y}_{C U_{V A}}=1\right)=\prod=\frac{\mathrm{E}^{\beta 0+\beta_{1} G+\beta_{2} R A C E+\beta_{3} H A R D D R U G+\beta_{4} \text { OHUSE + } e}}{1+\mathrm{E}^{\beta 0+\beta_{1} G+\beta_{2} R A C E+\beta_{3} H A R D D R U G+\beta_{4} \text { OHUSE +e }}}
$$

This is a significant model and explained $5.2 \%$ of the variability of risky sexual behavior $\left(\mathrm{R}^{2}=.052\right)$. The AIC test suggests that the model fit the data appropriately since criterion value was reduced with covariates (intercept only model $=10362.983$ vs. intercept and covariate model value $=10047.450)$. Alcohol and illicit drugs were both significantly associated with engaging in vaginal sex without using condoms even after

controlling for race/ethnicity and gender. The parameter estimate for alcohol is $\beta=,-0.006$ (Wald $=83.63, p<.0001)$ and indicates that the odds of using a condom for vaginal sex decreased by a factor of 0.99 for every alcoholic drink reported. Likewise the odds on using a condom for vaginal sex by drug users were 0.59 times the odds of a non-drug user. In other words, drug users were $71 \%$ more likely to engage in unprotected vaginal $\operatorname{sex}\left(\frac{2.51}{1+2.51}=.71\right)$

The results suggest that the different ethnic/ racial groups have different probabilities of engaging in condom use. When comparing Latinos and African Americans to the referent group Others, Latinos and African Americans were roughly equivalent. That is in both groups the odds of reporting condom use were $\approx 1.18$ times the 
odds of the Other group reporting condom use. The odds of a male using a condom was 1.33 times the odds of a female reporting condom use. In other words, males were also 81 $\%$ more likely to report condom use when engaging in vaginal $\operatorname{sex}\left(\frac{4.24}{1+4.24}=.81\right)$. The complete results from this regression's analysis are shown in Table 4.

Table 4

Among Adolescent Detainees, the Association of Alcohol and Drug Use with Not Using a Condom for Vaginal Sex When Controlling for Gender and Race/Ethnicity

\begin{tabular}{lllll}
\hline Variable & B & Wald & Odds Ratio & P value \\
\hline Constant & .144 & 318.37 & 4.243 & $<.0001$ \\
Gender & 0.283 & 106.27 & 1.328 & $<.0001$ \\
Race/White & -0.054 & 1.096 & 0.947 & .295 \\
Race/African American & 0.167 & 15.48 & 1.182 & $<.0001$ \\
Race/Latino & 0.164 & 15.06 & 1.179 & .0001 \\
Illicit drugs & -.526 & 37.19 & .591 & $<.0001$ \\
Alcohol & -0.006 & 83.63 & .994 & $<.0001$ \\
\end{tabular}

The second equation used to examine the first model was the following:

$$
\left.\operatorname{prob} \hat{\mathrm{Y}}_{C U_{O R}}=1\right)=\prod=\frac{\mathrm{E}^{\beta 0+\beta_{1} G+\beta_{2} R A C E+\beta_{3} H A R D D R U G \beta_{4} \text { OHUSE }}{ }^{e}}{1+\mathrm{E}^{\beta 0+\beta_{1} G+\beta_{2} R A C E+\beta_{3} H A R D D R U G \beta_{4} \text { OHUSE } e}}
$$

Equation $1 \mathrm{~b}$ explained $\approx 19 \%$ of the variance in risky sexual behavior (not using a condom) when engaging in oral sex $\left(\mathrm{R}^{2}=18.9\right)$. The model produced a good fit to the 
data as suggested by the AIC test results (intercept only model $=3534.265$, intercept and covariates model $=3055.861)$. In this model, the results suggest that the race/ethnic groups have different probabilities of not using a condom when engaging in oral sex. The odds on using a condom for oral sex by Latinos were $\approx 0.16$ the odds of Others reporting condom use $(\mathrm{OR}=0.159, \mathrm{Wald}=101.00, p<.0001)$. However, the odds on using a condom for oral sex by African Americans were 2.02 greater than the odds of Others reporting condom use for oral sex. $(\mathrm{OR}=2.022, \mathrm{Wald}=51.79, p<.0001)$. In this regression, the odds of using a condom for oral sex by males were less than the odds of a female reporting the use of a condom by a factor of $0.87(\mathrm{OR}=0.872$, Wald $=8.04, \mathrm{p}=0.004)$ Similar to condom use during vaginal sex, the odds of using a condom for oral sex decreased by a factor of 0.99 for every alcoholic drink reported $(\mathrm{OR}=0.990$, Wald $=$ $20.79, \mathrm{p}<0.0001)$. The odds of using a condom for oral sex by drug users was 0.46 times the odds of a non-drug user $(\mathrm{OR}=0.462$, Wald $=46.90, \mathrm{p}<0.0001)$. Detailed results from equation $1 \mathrm{~b}$. are shown in Table 5 in the next page.

The third logistic regression examined the association between drug and alcohol use and condom use when engaging in anal sex after controlling for race and race/ethnicity. The third regression was the following:

$$
\operatorname{prob}\left(\hat{\mathrm{Y}}_{C U_{A N}}=1\right)=\prod=\frac{\mathrm{E}^{\beta 0+\beta_{1} G+\beta_{2} R A C E+\beta_{3} \text { OHUSE }+e}}{1+\mathrm{E}^{\beta 0+\beta_{1} G+\beta_{2} R A C E+\beta_{3} \text { OHUSE }+e}}
$$

The results of the AIC test suggests that the model fit the data adequately (intercept model only $=429.259$, intercept and covariates model $=253.871)$.

Regression 1c. explained $5.8 \%$ of the variance in risky sexual behavior when 
engaging in anal sex $\left(R^{2}=.0585\right)$. In this logistic regression, being male and White were associated with engaging in unprotected anal sex. As shown in Table 6 , the odds on using a condom for anal sex by Whites were 0.14 the odds of Others reporting condom use $(\mathrm{OR}=0.142$, Wald $=34.09, p<.0001)$. The odds for condom use reported by males increased by a factor of 3.67 compared to the odds of women reporting condom use for anal sex $(\mathrm{OR}=3.67$, Wald $=11.70, \mathrm{p}=$ 0.0006). In other words, males were $96 \%\left(\frac{27.70}{1+27.70}=.96\right)$ more likely than females to report not using condoms when engaging in anal sex.

Table 5

Among Adolescent Detainees the Association of Alcohol and Drug Use with Not Using a Condom for Oral Sex When Controlling for Gender and Race/Ethnicity

\begin{tabular}{lcccc}
\hline Variable & \multicolumn{2}{c}{ Wald } & Odds Ratio & $p$ value \\
\hline Constant & -1.464 & 179.50 & .231 & $<.0001$ \\
Gender & -.1374 & 8.04 & .872 & .004 \\
White & .019 & .033 & 1.01 & .854 \\
African American & .704 & 51.79 & 2.02 & $<.0001$ \\
Latino & -1.840 & 101.00 & .159 & $<.0001$ \\
Illicit drugs & -.773 & 46.90 & .462 & $<.0001$ \\
Alcohol & -.010 & 20.79 & .990 & $<.0001$ \\
\end{tabular}


The odds of using a condom for anal sex increased by a factor of 6.2 for every alcoholic drink reported $(\mathrm{OR}=6.19$, Wald $=10.53, \mathrm{p}=0.0012)$. Alcohol use increased the odds of using a condom for anal sex. Perhaps this is because very few participants engaged in anal sex, and alcohol use was measured as the number of drinks consumed. Across the range of drinks consumed, the cell counts may be sparse and the estimates not as robust as those from a larger sample.

Table 6

Among Adolescent Detainees, the Association of Alcohol and Drug Use with Not Using a Condom for Anal Sex when Controlling for Gender and Race/Ethnicity

\begin{tabular}{lllll}
\hline Variable & B & Wald & Odds Ratio & P value \\
\hline Constant & 3.321 & 26.31 & 27.70 & $<.0001$ \\
Gender & -1.300 & 11.70 & .272 & .00006 \\
Race/Latino & .2141 & .599 & 1.23 & $<.0001$ \\
Race/White & -1.95 & 34.09 & .142 & $<.0001$ \\
Race/African American & .944 & 4.147 & 2.57 & .0417 \\
Alcohol & 1.823 & 10.53 & 6.193 & .0012 \\
\hline
\end{tabular}

Race/ethnicity has an association with not using condoms. The odds on using a condom for anal sex by Whites were 7.03 the odds of Others reporting condom use $(\mathrm{OR}=7.03$, Wald $=34.09, p<0.0001)$. However, the odds on reporting condom use for anal sex by Latinos were 0.81 the odds of Others reporting 
condom use $(\mathrm{OR}=0.807, \mathrm{Wald}=0.599, p<0.0001)$. More information about the results of this regression can be found in Table 6 .

\section{Model Two:}

Three logistic regressions were also used to address the second research question: Is the level of (a) sexual behavior attitudes, (b) level of HIV knowledge, (c) condom use attitudes, and (d) the level of skills to use a condom related to the level of detained adolescents' condom use when controlling for gender and race/ethnicity? The equation for the logistic regression used to address these questions for vaginal sex is given as:

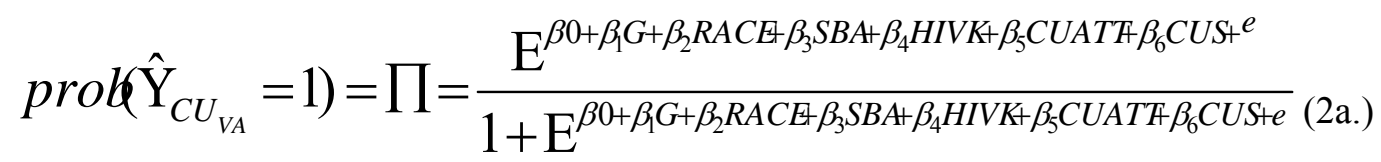

The results of equation $2 \mathrm{a}$. explained $9.5 \%$ of the variance in condom use when engaging in vaginal sex $\left(\mathrm{R}^{2}=.095\right)$. This model produced a good fit to the data as seen by the results of the AIC test (intercept only model $=10581.305$, vs. intercept and covariates model $=9984.186$ ). These results indicate that sexual behavior attitudes, condom use attitudes and condom use skills were associated with condom use during vaginal sex. In this logistic regression, being male, African American and Latino were also associated with engaging in condom use during vaginal sex. The odds of using a condom increases by 1.27 times for every unit increase in the positive sexual attitude score $(\mathrm{OR}=1.269$, Wald $=29.73$, $p<.0001)$. For condom use skills every unit increase in the score increased the odds of using a condom by 1.07 times $(\mathrm{OR}=1.072$, Wald $=38.75, p<.0001)$. The odds of condom use for vaginal sex increased by 3.68 times for every unit 
increase in the score on the condom use attitudes scale $(\mathrm{OR}=3.68$, Wald $=$ $218.87, \mathrm{p}, 0.0001)$. The odds of condom use with vaginal sex by men was found to be greater than of women by a factor of 1.34 times $(\mathrm{OR}=1.34$, Wald $=109.31, \mathrm{p}$ $<0.0001)$.

There was also a small difference among race/ethnicity groups. When comparing African American and Latinos to the referent group Others, both were 1.1 times more likely to use condoms during vaginal sex. None of the other indicators were related to condom use during vaginal sex. The complete results of logistic regression 2a. are given in Table 7.

Table 7

Among Adolescent Detainees, the Association of Attitude and Knowledge Indicators with Not Using a Condom for Vaginal Sex when Controlling for Gender and Race/Ethnicity

\begin{tabular}{lclcc}
\hline Variable & \multicolumn{1}{l}{ B } & Wald & Odds Ratio & $p$ value \\
\hline Constant & 3.59 & 162.09 & .027 & $<.0001$ \\
Gender & .294 & 109.31 & 1.34 & $<.0001$ \\
Race/White & .076 & 2.024 & 1.07 & .154 \\
Race/African American & .104 & 5.689 & 1.11 & .017 \\
Race/Latino & .150 & 12.523 & 1.16 & .0004 \\
Sex Attitudes & .238 & 29.73 & 1.26 & $<.0001$ \\
HIV Knowledge & -.084 & 64.31 & .919 & $<.0001$ \\
Condom attitude & 1.303 & 218.87 & 3.68 & $<.0001$ \\
Condom Use Skills & .069 & 38.75 & 1.07 & $<.0001$ \\
\hline
\end{tabular}


The equation for the logistic regression used to address the second question for oral sex is given as:

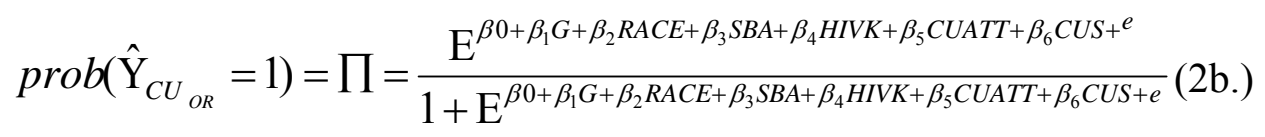

The model expressed in equation $2 b$ explained $20.5 \%$ of the variance in condom use for oral sex $\left(\mathrm{R}^{2}=.205\right)$. The model produced an adequate fit to the data as seen by the results of the AIC test (intercept only model $=3575.255$, vs. intercept and covariates model $=3048.755)$. These results indicate that condom attitudes and condom use skills were associated with condom use during oral sex. The odds of using a condom for oral sex increased by a factor of 1.52 times for each unit increase in the condom attitudes score $(\mathrm{OR}=1.52$, Wald $=8.73, \mathrm{p}=0.003)$.

Similarly, the odds of using a condom for oral sex increased by a factor of 1.09 times for each unit of increase in the condom use skills score $(\mathrm{OR}=1.09$, Wald $=$ 16.95, $p<.0001)$.

In regression $2 b$, the odds of using a condom for oral sex among males was less than that among females by a factor of $0.66(\mathrm{OR}=.662$, Wald $=61.69$, $p<.0001)$. Additionally, when compared to Others, the odds of using a condom for oral sex decreased by a factor of 0.02 in Latinos $(\mathrm{OR}=.017$, Wald $=62.31$, $p<.0001)$. However, the odds of reporting condom use for oral sex by African Americans were 1.44 times the odds of Others reporting condom use $(\mathrm{OR}=1.44$, Wald=13.32, $p<0.0001)$. Complete details on the results of this regression are in Table 8 . 
The equation for the logistic regression equation used to address these questions for anal sex is given as:

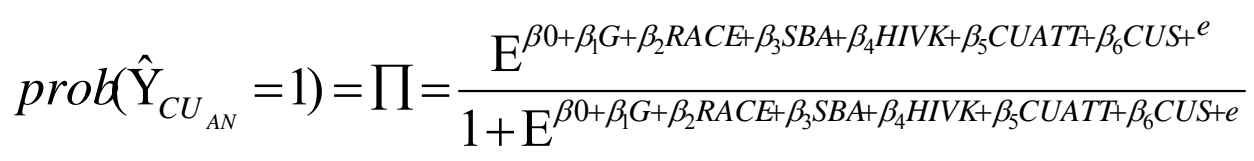

The model expressed in equation $2 \mathrm{c}$. explained $5.8 \%$ of the variance in condom use for anal sex $\left(\mathrm{R}^{2}=.0581\right)$. This logistic regression model produced an adequate fit to the data as seen by the results of the AIC test (intercept only model = 432.940, vs. intercept and covariates model $=263.210)$.

These results indicate that condom attitudes and sexual attitudes were associated with condom use during anal sex. The odds of using a condom for anal sex increased by a factor of 11.6 times for each unit increase in the condom attitudes score $(\mathrm{OR}=11.95, \mathrm{Wald}=7.85, \mathrm{p}=0.005)$. In contrast, the odds of using a condom for anal sex decreased by a factor of 0.28 times for each unit of increase in the sex attitudes score $(\mathrm{OR}=0.285$, Wald $=13.81, p=0.0002)$.

The odds of using a condom for anal sex among males was less than that among females by a factor of $0.19(\mathrm{OR}=0.188$, Wald $=16.55, p<0.0001)$. In other words, Males were 57\% more likely to engage in unprotected sex. When compared to Others, the odds of using a condom for anal sex decreased by a factor of 0.12 in Whites $(\mathrm{OR}=.017$, Wald $=62.31, p<.0001)$. However, the odds of reporting condom use for anal sex by African Americans were 3.93 times the odds of Others reporting condom use $(\mathrm{OR}=3.93$, Wald $=7.56, p<0.006)$. 
Table 8

Among Adolescent Detainees the Association of Attitude and Knowledge Indicators with Not Using a Condom for Oral Sex when Controlling for Gender and Race/Ethnicity

\begin{tabular}{lllll}
\hline Variable & B & Wald & Odds Ratio & P value \\
\hline Constant & -.304 & .387 & .073 & .533 \\
Gender & -.413 & 61.69 & .662 & $<.0001$ \\
Race/White & .204 & 3.75 & 1.22 & .052 \\
Race/African American & .370 & 13.32 & 1.44 & .0003 \\
Race/Latino & -1.72 & 92.31 & .178 & $<.0001$ \\
Sex attitudes & -.026 & .066 & .974 & .796 \\
HIV Knowledge & -.261 & 143.93 & .770 & $<.0001$ \\
Condom attitude & .424 & 8.73 & 1.52 & .003 \\
Condom Use Skills & .087 & 16.95 & 1.09 & $<.0001$ \\
\hline
\end{tabular}

\section{Model Three}

Three logistic regression equations were fitted to the data to examine the third research question: Is the level of (a) peer approval of condom use, (b) parental approval of condom use, (c) alcohol use, (d) use of drugs (marijuana, cocaine and other drugs), related to condom use for vaginal, oral, and anal sexual activity when controlling for gender and race/ethnicity? The equation for the logistic regression used to address this research question for vaginal sex is given as: 


$$
\operatorname{prob}\left(\hat{\mathrm{Y}}_{C U_{V A}}=1\right)=\prod=\frac{\mathrm{E}^{\beta 0+\beta_{1} G+\beta_{2} R A C E+\beta_{3} A F P E+\beta_{3} \mathrm{OHUSE}+\beta_{5} H A R D D R U G+\beta_{6} A F P A+}{ }^{e}}{1+\mathrm{E}^{\beta 0+\beta_{1} G+\beta_{2} R A C E+\beta_{3} A F P E+\beta_{4} O H U S E+\beta_{5} H A R D D R U G+A F P A+e}}
$$

The model expressed in equation 3a. explained $5.7 \%$ of the variance in condom use for oral sex $\left(\mathrm{R}^{2}=.057\right)$. This regression model produced an adequate fit for the data as seen by the results of the AIC test (intercept only model $=10264.485$, vs. intercept and covariates model $=9922.978)$. These results indicate that alcohol and illicit drug use were associated with less condom use during vaginal sex.

The odds ratio for alcohol indicates that the odds of using a condom for vaginal sex decreased by a factor of 0.99 for every alcoholic drink reported $(\mathrm{OR}=0.994$, Wald $=$ 77.54, $\mathrm{p}<0.0001)$. Likewise, the odds of using a condom for vaginal sex by drug users were 0.59 the odds of a non-drug user $(\mathrm{OR}=.596$, Wald $=35.97, p<.0001)$. In other words, of the participants who had one drink of alcohol, $83 \%$ were less likely to use condoms during vaginal sex. Similarly, of the participants who reported illicit drug use, $75 \%$ had more likelihood of not using condoms during vaginal sex.

The odds of using a condom by males for vaginal sex were 1.32 times the odds for females $(\mathrm{OR}=1.328$, Wald $=104.19, p<.0001)$. Additionally, the odds of using a condom for vaginal sex by Latinos was $1.2(\mathrm{OR}=1.20$, Wald $=18.86, p<0.0001)$ and $1.17(\mathrm{OR}=1.172$, Wald $=13.87, p<.0001$ when compared to the odds of Others using a condom for vaginal sex. Results from equation 3a. also showed that the odds of using a condom for vaginal sex increased by a factor of 1.16 for every unit increase in the peer approval score $(\mathrm{OR}=1.162$, Wald $=20.42, p<.0001)$. In contrast, the odds of using a condom for vaginal sex decreased by a factor of 0.83 for every unit increase in the 
parental approval score $(\mathrm{OR}=0.830$, Wald $=27.41, p<.0001)$. Detailed results from this equation are shown in Table 10.

Table 9 provides detailed information about the use of condoms during anal sex. More explanation of these results can be found in the discussion section. Table 9.

Among Adolescent Detainees the Association of Attitude and Knowledge Indicators with Not Using a Condom for Anal Sex when Controlling for Gender and Race/Ethnicity

\begin{tabular}{lllll}
\hline Variable & B & Wald & Odds Ratio & P value \\
\hline Constant & .268 & .013 & 1.308 & .0908 \\
Gender & -1.67 & 16.55 & .188 & $<.0001$ \\
Race/White & -2.14 & 20.55 & .117 & $<.0001$ \\
Race/African American & 1.36 & 7.56 & 3.935 & .006 \\
Race/Latino & -.106 & 10.81 & .346 & .001 \\
Sex attitudes & -1.25 & 13.81 & .285 & .0002 \\
HIV Knowledge & .036 & .187 & 1.038 & .665 \\
Condom attitude & 2.48 & 7.85 & 11.95 & .005 \\
Condom Use Skills & -.139 & 1.49 & .870 & .221 \\
\hline
\end{tabular}

The model expressed in equation $3 \mathrm{~b}$. explained $25 \%$ of the variance in condom use during oral sex $\left(\mathrm{R}^{2}=.25\right)$. This regression model produced an adequate fit for the data as seen by the results of the AIC test (intercept only model $=3498.542$, vs. intercept and covariates model $=2858.358)$. 
The equation for the logistic regression used to address the research question for oral sex is given as:

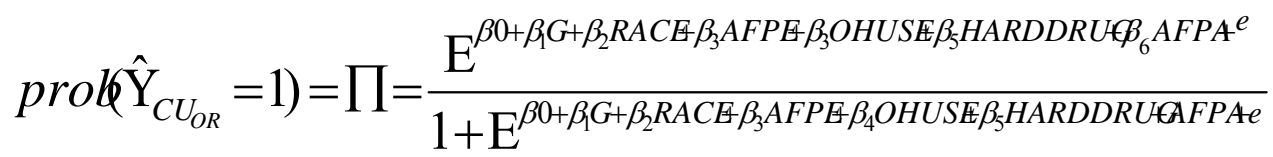

Table 10.

Among Adolescent Detainees, the Association of Peer and Parental Approval, Alcohol

Use and Drug Use with Not Using a Condom for Vaginal Sex when Controlling for Gender and Race/Ethnicity

\begin{tabular}{lllll}
\hline Variable & B & Wald & Odds Ratio & $p$ value \\
\hline Constant & 1.63 & 60.47 & 5.11 & $<.0001$ \\
Gender & .283 & 104.19 & 1.32 & $<.0001$ \\
Race/White & -.079 & 2.27 & .924 & .013 \\
Race/African American & .159 & 13.87 & 1.172 & .000 \\
Race/Latino & .188 & 18.86 & 1.20 & $<.0001$ \\
Peer approval & .150 & 20.42 & 1.16 & $<.0001$ \\
Parental approval & -.186 & 27.41 & .830 & $<.0001$ \\
Alcohol & -.006 & 77.54 & .994 & $<.0001$ \\
Illicit drugs & -.518 & 35.97 & .596 & $<.0001$ \\
\hline
\end{tabular}

The odds of using a condom for oral sex by drug users were 0.42 the odds of a non-drug user $(\mathrm{OR}=0.424, \mathrm{Wald}=55.06, p<0.0001)$. When compared to 
Others, Whites and African Americans were more likely to use condoms when engaging in oral sex by factors of $1.5(\mathrm{OR}=1.55$, Wald $=15.24, p<0.0001)$ and $1.8(\mathrm{OR}=1.81, \mathrm{Wald}=34.20, p<0.0001)$ respectively. The odds of using a condom for oral sex decreased by a factor of 0.12 times for each unit increase in the peer approval score $(\mathrm{OR}=0.118, \mathrm{Wald}=126.88, \mathrm{p}=0.0001)$. In contrast, the odds of using a condom for oral sex increased by a factor of 1.67 times for each unit of increase in the parental score $(\mathrm{OR}=1.67$, Wald $=19.95, p<0.0001)$. More detailed results of this regression are found in Table 11.

The equation for the logistic regression used to address the research question for anal sex is given as:

$$
\operatorname{prob}\left(\hat{\mathrm{Y}}_{C U_{A N}}=1\right)=\prod=\frac{\mathrm{E}^{\beta 0+\beta_{1} G+\beta_{2} R A C E+\beta_{3} A F P E+\beta_{3} \mathrm{OHUSE}+\beta_{5} A F P A+e}}{1+\mathrm{E}^{\beta 0+\beta_{1} G+\beta_{2} R A C E+\beta_{3} A F P E+\beta_{4} \mathrm{OHUSE}+\beta_{5} A F P A+e}}
$$

(3c).

The regression equation of the model expressed in equation $3 \mathrm{c}$. explained $6.8 \%$ of the pseudo variance in condom use for anal sex $\left(\mathrm{R}^{2}=.68\right)$. This regression model produced an adequate fit for the data as seen by the results of the AIC test (intercept only model $=429.259$, vs. intercept and covariates model $=214.463$ ).

When compared to Others, the odds of condom use when Whites and Latinos engaged in anal sex were 0.26 times $(\mathrm{OR}=0.265$, Wald $=13.31, p<$ $0.0003)$ and 0.36 times $(\mathrm{OR}=0.357, \mathrm{Wald}=6.77, p<0.009)$ the odds of Others using condoms during anal sex. In contrast, when African Americans were compared to Others, the odds of condom use for anal sex was 4.18 times the odds of condom use for Others $(\mathrm{OR}=4.185$, Wald $=8.72, \mathrm{p}<0.003)$. The odds of 
condom use in males was 0.12 times the odds of condom use for anal sex among females $(\mathrm{OR}=0.121$, Wald $=24.43, \mathrm{p}<0.0001)$.

Table 11.

Among Adolescent Detainees the Association of Peer and Parental Approval, Alcohol Use and Drug Use with Not Using a Condom for Oral Sex when Controlling for Gender and Race/Ethnicity

\begin{tabular}{lllll}
\hline Variable & B & Wald & Odds Ratio & $p$ value \\
\hline Constant & .601 & 1.30 & 1.82 & .252 \\
Gender & .057 & 1.18 & 1.05 & .277 \\
Race/White & .440 & 15.24 & 1.55 & $<.0001$ \\
Race/African American & .598 & 34.20 & 1.81 & $<.0001$ \\
Race/Latino & -2.13 & 126.88 & .118 & $<.0001$ \\
Peer approval & -1.02 & 158.67 & .358 & $<.0001$ \\
Parental approval & .514 & 19.95 & 1.67 & $<.0001$ \\
Alcohol & -.005 & 5.33 & .995 & .020 \\
Illicit drugs & -.856 & 55.06 & .424 & $<.0001$ \\
\hline
\end{tabular}

Results also showed that the odds of using a condom for anal sex decreased by a factor of 0.36 times for each unit increase in the peer approval score $(\mathrm{OR}=0.364, \mathrm{Wald}=25.44, \mathrm{p}=0.0001)$. The odds of using a condom for anal sex increased by a factor of 6.62 times for each alcoholic drink increase $(O R=$ 6.62, Wald=12.21, $p<0.0005)$. 
These results may have been due to the small number of participants who engaged in anal sex and the fact that $76 \%$ of the participants who engaged in anal sex used condoms. More details about the results of this equation can be found in Table 12.

Table 12.

Among Adolescent Detainees, the Association of Peer and Parental Approval, Alcohol Use and Drug Use with Not Using a Condom for Anal Sex when Controlling for Gender and Race/Ethnicity

\begin{tabular}{lcccc}
\hline Variable & B & Wald & Odds Ratio & $p$ value \\
\hline Constant & 7.955 & 19.54 & 28.52 & $<.0001$ \\
Gender & -2.110 & 24.43 & .121 & $<.0001$ \\
Race/White & -1.326 & 13.31 & .265 & .0003 \\
Race/African American & 1.431 & 8.72 & 4.185 & .003 \\
Race/Latino & -1.029 & 6.77 & .357 & .009 \\
Peer approval & -1.011 & 25.44 & .364 & $<.0001$ \\
Parental approval & .0130 & .356 & 1.139 & .550 \\
Alcohol & 1.890 & 12.21 & 6.62 & .0005 \\
\hline
\end{tabular}

\section{Summary}

When examining condom use in the first model equation (1a, 1b, and 1c), alcohol use was the common covariate that increased the likelihood of engaging in risky sexual behavior for vaginal, oral and anal sex. Illicit drug use increased the likelihood of 
engaging in unprotected vaginal and oral sex. Males reported more condom use only during vaginal sex; they were less likely to use condoms during oral and anal sex. Furthermore, the results of the first model equations indicated that African Americans and Latinos were more likely than those in the Other group to use condoms during vaginal sex. While being African American was also associated with a higher likelihood of using condoms during oral sex, Latinos were less likely to use condoms than Others in the comparison group. Lastly, Whites were more likely not to use condoms during anal sex when compared to Others in the first equation model. In sum, males were more likely to use condoms during vaginal sex and less likely to use condoms during oral sex and anal. The use of alcohol was the only covariate that was significantly associated with unprotected vaginal, oral and anal sex.

The results from the second equation models $(2 \mathrm{a}, 2 \mathrm{~b}$, and $2 \mathrm{c}$.) indicate that condom use attitudes was the common covariate that decreased the likelihood of engaging in risky sexual behavior for vaginal, oral, and anal sex. Condom use skills decreased the likelihood of engaging in unprotected vaginal and oral sex. Similar to results in equation 1a, males reported greater probability of condom use only during vaginal sex; they were less likely to use condoms during oral and anal sex. Furthermore, the results of the first model equations indicated that African Americans were more likely than Others to use condoms during vaginal sex. While African Americans were also associated with a higher likelihood of using condoms during oral sex, Latinos were less likely to use condoms than Others in the comparison group. That result also corresponds to equations 1a. and $1 \mathrm{~b}$. from the first model. Lastly, Whites and Latinos were more likely not to use condoms during anal sex when compared to Others in the second 
equation model. These results are analogous to the first equation model for anal sex. Lastly, similar to the results from equation 1a, males were more likely to use condoms during vaginal sex (2a) and less likely to use condoms during oral and anal sex (equations 1b., 2b, 1c, and 2c). In sum, condom use attitudes and condom use skills were the two covariates that were significantly associated with protected vaginal, oral, and anal sex.

When examining condom use in the third model equation (3a, 3b, and 3c), alcohol use was the common covariate that increased the likelihood of engaging in risky sexual behavior for vaginal and anal sex. Illicit drug use increased the likelihood of engaging in unprotected vaginal and oral sex. Males reported more condom use only during vaginal sex but they were less likely to use condoms during oral and anal sex. Furthermore, the results of the first model equations indicated that African Americans and Latinos were more likely than Others to use condoms during vaginal sex. While African Americans were also associated with higher likelihood of using condoms during oral sex, Latinos were less likely to use condoms than Others in the comparison group. Lastly, similar to results in the first model (1c), Whites were more likely not to use condoms during anal sex when compared to Others. In sum, the results from the first and the third equation model are equivalent in regards to gender and risky sexual behavior. Males were more likely to use condoms during vaginal sex and less likely to use condoms during anal sex. The results from the third model examining vaginal sex (3a.) indicates that parents approval to use condoms was significantly associated with less likelihood of condom use during vaginal sex among participants. However, peer approval to use condoms was associated with higher likelihood of condom use during vaginal sex. Lastly, in the third equation, peers approval to use condoms decreased the likelihood of condom use. 
In summary, these results indicated that covariates association can vary based on the type of sexual behavior within each model. An example is that illicit drug use is not significantly associated with unprotected anal sex although it increased the likelihood of unprotected sex during vaginal and oral sex. Similarly, condom use skills were significantly associated with more likelihood of condom use during vaginal and oral sex but not significantly associated with using condoms for anal sex. Higher scores in the condom use attitude scale (in the second equation model) increased the likelihood of using condoms during vaginal and oral sex, but were related to decreased likelihood of using condoms during anal sex.

When compared to Others, Blacks and Latinos were more likely to use condoms during vaginal sex in all the models. Additionally, Whites, when compared to Others were less likely to use condom use during anal sex in all three models. However, during oral sex, Latinos were more likely than Others to engage in unprotected oral sex during the three equation models. Whites and Latinos are associated with not using condoms during oral and anal sex, suggesting that White and Latinos may be less likely than Others to engage in protected sex. These results are consistent with the researcher's hypothesis that levels of sexual risk behaviors among detained adolescents were going to vary according to the different racial/ethnic groups among other covariates. The following chapter will discuss further the implications of the current study. 


\section{CHAPTER V \\ DISCUSSION}

The purpose of this dissertation has been to examine the relationship among detained adolescent substance use, their sexual risk behaviors, condom use attitudes, sexual risk attitudes, condom use skills, HIV knowledge and their perceived peer and parental support to use condoms. The research questions stated on Chapter 2 (page 39).were examined using the HBM as a guide as explained in chapters 1 and 2. This chapter is structured by: 1) a discussion of the results, 2) a listing of the limitations of the study, 3) suggestions of possible implications for social work and public health policy, 4) suggestions of plausible implications for social work and public health practice, 5) possible implications for future research, and 6) a summary section.

\section{Discussion of Results}

The primary goal of this dissertation has been to investigate if substance use was associated to the sexual risk behaviors. Results from the current cross-sectional study indicate that for these detained adolescents, the use of alcohol was significantly associated with risky sexual behavior during vaginal, oral, and anal intercourse. These findings support previous research documenting that the use of alcohol and other drugs is associated with vaginal risky sexual behavior problems among adolescents (Coleman \& Cater, 2005; Kingree \& Phan, 2001).

It was hypothesized that both gender and race/ethnicity were going to affect the probabilities of risky sexual behavior. Further, the results suggest that race/ethnicity differences in condom use exist in the current study's sample. For example, both African Americans and Latinos were more highly associated with protected vaginal intercourse 
when compared to individuals in the Other racial/ethnic group. It should be noted that as expected, positive sexual attitude scores were also significantly related to condom use during vaginal sex even after controlling for race/ethnicity and gender.

Although these results are inconsistent with Kingree and Betz's (2003) study in which marijuana rather than alcohol was more significantly associated with risky sexual behaviors, alcohol was found to be significant and to decrease the likelihood to use condoms in all the regression equations for Model One, Two and Three (vaginal, oral, and anal sex). Therefore, alcohol use helped explain the variability of sexual risk behaviors for this sample and it was one of the most influential variables when the first model was examined (equations 1a, 1b, 1c).

Due largely to the low number of participants who engaged in anal sex and the high level of condom use among them resulted in the equation for anal sex showing a significant association in which alcohol use increased the likelihood of condom use during anal sex. The fact that illicit drug use decreased the use of a condom for vaginal and oral sex is important because more adolescents in this study reported higher use of illicit drugs during the 6 months prior to the parent study ( $80.6 \%$ used illicit drugs versus $60.4 \%$ used alcohol). It is possible that alcohol is more significant for the adolescents in this sample who were at risk of engaging in oral risky sex since the probability of engaging in risky sex was usually higher for alcohol use than for drug use (i.e., $81 \%$ versus $71 \%$ for vaginal sex, and $81 \%$ versus $10 \%$ in oral sex). However, it should be noted that this finding is consistent with many other studies that have associated alcohol with permissiveness for deviant behaviors, decreased inhibitions, and the inability to use proper judgment (Coleman \& Cater, 2005; Fromme, D'Amico, \& Katz, 1997). 
Results of the current study may demonstrate and extend the applicability of some of the HBM components, although they were only used as a guiding framework for their analysis and did not set out as a formal test of the HBM. The current study supports earlier literature (Kirscht, 1974; Rosenstock, 1974) that posits when people feel the threat of a negative health condition, and they believe taking action will prevent a negative condition, then they would be active. In examining condom use during vaginal, oral, and anal sex, more positive condom use attitude was significantly associated with higher likelihood of using condoms during these sexual encounters. Furthermore, condom use skills were significantly associated with condom use during vaginal and oral sex. In this case, the action is the adolescents' use of condoms and the negative condition is contracting HIV. Therefore, the current study's results may suggest an example that the HBM has application in that adolescents may have felt that they could prevent a negative health condition partly through their attitudes and actions.

These findings are consistent with the notion that the HBM prompt-to-action concept contributes to adolescents' use of condoms because the perceived approval or reinforcement to use condoms from peers (to prevent HIV infection) was significantly related to participants' use of condoms during vaginal sex. However, higher score levels of parental approval of condom use was significantly associated with lower likelihood to use condoms. In a similar fashion, perceived peer approval to use condoms was significantly associated with lower likelihood of using condoms during oral and anal sex. These results may be influenced by factors such as the low number of participants who engaged in oral sex with condoms and who had anal sex. 
It may also be that the results have been influenced by other personal characteristics of the participants and by other environmental factors related to parental approval of condom use. In other studies, poor parental monitoring has been associated with an increase of risky sexual behavior (e.g., DiClemente, 2001). Therefore, it is possible that detained adolescents, such as the ones in the current study, often have inappropriate parental supervision, and although they may be knowledgeable about their parents' level of approval of condom use, they would have more chances to engage in sexual behaviors and would therefore be expected to show higher rates of risky sexual behavior than non-detained adolescents.

Rosenstock (1974) believed that some appeals will not produce the desired effect, perhaps because of different prompt methods (personal interaction versus media exposure), the emotion that accompanies the message (high level of fear versus low fear level), and the fact that an individual goes through a number of internal stages before engaging in a behavior. Because the current study was done on a delinquent population, stimuli to engage in healthy behavior may not have produced the desired effect. Participants' personal characteristics, such as age, may have also had an effect.

As anticipated, condom use differed across racial/ethnic groups. When compared to Others (Haitian, Pacific Islanders, and non-Haitian Caribbean), African-Americans in this sample were significantly less likely to engage in risky sexual behavior (vaginal, oral, or anal). Perhaps there are other protective factors such as low incidence of alcohol use that need to be explored within the African American ethnic/racial group.

When comparing White with the Other racial/ethnic group, they were more likely to engage in risky behavior during vaginal and anal sex. Similarly Latinos were more 
likely to engage in oral and anal sex without protection when compared to Others. This finding may suggest that Latinos in the current study are behaving similar to Whites and engaging in unprotected anal sex at similar rate. These results may also be explained by the small number of participants who engaged in anal sex (12.5\% of the sample).

However, Latinos were also more likely to use condoms than the comparison group Other when having vaginal sex. In sum, Whites had higher risky sexual behaviors since they were more likely to engage in unprotected vaginal and anal sex. The second group with the highest sexual risky behaviors was Latinos since they had the highest likelihood of engaging in unprotected anal and oral sex.

It should be noted here that the results of the current study may be influenced by the number of Latinos who identify themselves as White in Miami-Dade-County. According to the 2000 census, $73-75 \%$ of the Miami-Dade County population reported being White at the same time that $67 \%$ identified themselves as Hispanic (United States Census, 2000). Furthermore, according to a report by the PEW Hispanic Center, in the 2000 census $85 \%$ of individuals with Cuban heritage identified themselves as White compared to $59 \%$ of those with South American heritage and only $47.2 \%$ of those with Puerto Rican heritage who did so (Sonya, 2004, p.8). This is important because most Latino participants in the sample for this study were Cuban immigrants or of Cuban descent and the majority of the Latino detainees of the JAC identified themselves as being Hispanic White. Therefore, it may be reasonable to assume that in Miami-Dade County, individuals who self identify as Latino may not be that different than Whites. Hence, the adolescents who identified themselves as Latinos would behave similar to their White counterparts and identify themselves as White. In Miami's JAC, these two 
groups may in fact blend into one similar group. There is a need to further investigate similar larger data sets in order to clarify this proposition and examine the difference in condom use.

The current study's results did not entirely support the hypothesis that illicit drugs would be one of the most significant covariates for all types of sexual encounters, instead, the use of alcohol was found to have the most significant association with the level of condom use during vaginal and oral sex. The alcohol use variable was consistently significant in the first and the third equation of the regression models (unprotected vaginal and oral sex) that were examined in the current study. Similar findings about alcohol association with risky vaginal sex have been found in other studies (Kingree \& Phan, 2001).

The result of the first model's (equation 1a) suggests that alcohol use increased the likelihood of detained adolescents' unprotected vaginal intercourse more than the use of illicit drugs. These results are similar to the studies of both Kingree and Phan (2001), and Kingree, Braithwaite, and Woodring (2002) which imply that alcohol has a greater association with sexual risk behaviors. However, the first model fully supports the hypothesis that illicit drugs (among other variables) would be associated risky sexual behavior during vaginal and oral sex.

The current study's results show a difference between males and females while controlling for gender. However, other researchers have found that there is no significant differences between detained female and male adolescents' sexual risk behaviors (Morris, Harrison, Knox, \& Tromanhauser, 1995). There is evidence in the literature that regardless of their gender, individuals who exhibit delinquent behaviors, such as detained 
adolescents, initiate drug use and risky sexual behaviors at a relatively young age (Lederman, Dakof, Larrea, \& Hua, 2004; Morris et al., 1995). However, similar to the current study's findings, Lederman and colleagues (2004) have reported that compared to male adolescents, adolescent females have a higher rate of safe or protected sex ( $68 \%$ versus $48 \%$ ). These opposing findings suggest the need for further investigations with the inclusion of more detained females since they are typically under-represented in most studies of detained individuals, including the current one.

The results of this dissertation partially support the HBM applicability to guide sexual risky behavior components. These results also lend support to earlier research that posits people will act when they both feel that they can prevent a negative health condition (i.e., HIV) and believe that by taking action they will prevent it. Adolescents' positive attitudes toward sexual behavior in the current study were significantly associated with their use of condoms (an action taken to prevent a negative outcome from unprotected sex) during vaginal and anal sex. Furthermore, perceived approval to use condoms from peers support the guidance of the HBM prompt-to-action concept since even after controlling for gender and race/ethnicity, participants who received peer approval to use condoms had higher odds for using condoms during vaginal sex (equation regression 3a). These results support the current study's hypothesis. In a contrasting manner, when examining oral and anal sex, perceived peer approval of condom use was associated with higher likelihood of unprotected oral and anal sex. These results may be due to the small number of people who engaged in anal sex and the small number of participants who used condoms during oral sex. Additionally, other researchers have documented that the cues to action to engage in a healthy behavior and the perception of 
vulnerability are not sufficient for certain populations at high risk to act (DiClemente \& Peterson, 1994). Unlike peer approval of condom use, level of HIV knowledge was not significantly related to condom use for this sample. These results could have been created by the low variability in the sample since most of the participants reported high knowledge of HIV.

After preliminary analysis of the data in the current study, the researcher had anticipated that race/ethnicity would explain some of the variability of condom use. In fact, being White and Latino were found to be significantly associated to higher sexual risk behaviors in this sample. This finding may suggest that adolescents from other race/ethnicity categories such as the African-Americans could have socio-cultural protective factors although this could not be determined in the current study. Given that STD and HIV are usually a result of unprotected sexual behavior (risky sexual behavior), this study's findings are compatible with the Miami-Dade County data and the STD reports in which rates of sexually transmitted diseases among adolescent Latinos is the highest of all racial/ethnic groups (CDC, 2002). However, it was not possible to find a relationship between STD history and risky sexual behaviors in the current study due to the small number of STD in the sample. Future studies with larger samples can focus more on this area since adolescents in Miami-Dade have shown a disproportionately high rate of STD in general and those rates have been documented to be even higher among juvenile delinquents (FDH, 2004). Although similar to the county's latest demographic data on Latinos (34\%), further research should be done with larger samples and better assessment of STDs in order to better clarify the relationship between risky sexual behaviors and STD. 
Further, results suggest that there may be other psychosocial variables that were not included in the health belief theoretical model used to guide the analysis in the current study. Some of these factors have been found to be associated with sexual risk behaviors such as ecological and individual characteristics (Schumacher, Milby, Engle, \& Raczynski, 2000). Some of the individual characteristics that have been shown to have an effect on the variability of sexual risk behavior are the skills to negotiate safer sex and anger management skills (DiClemente \& Peterson, 1994). However, these variables were not measured during the baseline data collection of the parent study. In sum, to study the complex set of behaviors that make up sexual risk behavior may require a more comprehensive set of variables than the ones that have typically been employed (Kolbe, 1987) and the ones that were used in the current study.

\section{Limitations of the Study}

A primary limitation of this study is that it was not based on a randomly selected sample. Therefore, generalizability of its findings is limited and caution is advised when generalizing from the results. The sample and the inclusion criteria may limit generalization of the study results to adolescent detainees with those characteristics. Although most detained adolescents who were approached and asked to participate in the study volunteered to do it, the sample was composed only of detained adolescents at the Miami-Dade Juvenile Detention Centers who agreed to participate in the study. The researcher concluded that the sample was likely representative of the English speaking detained adolescents in Miami-Dade County Florida since similar to the study sample, the county's detained adolescent population (2003-2004) was composed of mostly Latinos and African-Americans detainees ( $34 \%$ and $48 \%$ respectively). Finally, female 
detainees represented 33\% of the detained population (Department of Juvenile Justice, 2006 ) and $25.9 \%$ of the study subjects. However, the sample was limited to the Englishspeaking adolescents, which could have excluded a sizable population of adolescents who primarily spoke Spanish or another language.

Another limitation of the study is that the data were based on self-report. Validating those self-report sexual risky behaviors is difficult because there were not biological tests in this study that could fully detect a past or present diagnosis of STD, which is a sexual risk behaviors consequence (Brener, Billy, \& Grady, 2003). In other words, it was impossible to detect if participants were lying about ever having been diagnosed with an STD or if they had one at the time of the study. However, there are a few advantages to the face-to-face interviews used in the parent study to collect selfreported sexual risk behaviors such as the ability of the researcher to build rapport with participants and to probe ambiguous or inconsistent responses. Face-to-face interviews also can enhance the researcher's ability to explain unfamiliar terms and decrease the number of participants in the study who may not respond during a self administered questionnaire (Weinhardt, Forsyth, Carey, \& Jaworski, 1998). Therefore, it should be noted that the fact that all assessments were conducted orally facilitated the accuracy of reporting, maximized data collection completion, and compensated for any subject illiteracy.

Since this study was based on a secondary data analysis, in order to minimize the limitation of misinterpreting data codes, and to enhance the data cleaning process, the researcher maintained correspondence with the investigators from the original parent study and with one of the interviewers. A copy of the code book was also obtained from 
the parent study. Nonetheless, it must be noted that the present study's sample and data collection quality was limited by procedures followed and data collected in the parent study. In conclusion, although this study presents a number of limitations, it also has important implications and contributions to social work practice, policy formulation, and future research studies.

\section{Implications for Social Work and Public Health Policy}

From a policy perspective, the study's findings suggest that alcohol use increases adolescents' likelihood to engage in high risky sexual behaviors (vaginal, anal and oral). Although there are physiological and psychological factors that have an effect on these kinds of health risk behaviors (Schumacher, Milby, Engle, \& Raczynski, 2000), the psychosocial behavioral variables examined in the current study are critical to understand risky sexual behaviors among these adolescents. The three models examined demonstrated appropriate fit to the data although some of them did not explain a high degree of variability in the dependent variables. The study's findings support other research findings concerning alcohol and risky sexual behavior (Dembo et al., 1990). The current study's results indicate that positive sexual attitudes are significantly associated with safer vaginal sex among adolescent detainees (equations 1a and 2a). Positive condom use attitudes were also significantly associated with safer vaginal, oral and anal sex. Therefore, it is imperative that interventionists learn about the association between positive attitudes and healthy sexual behaviors among adolescent detainees.

The rehabilitation intervention programs (which include increasing positive attitudinal changes about health behaviors) available to adolescent detainees should be well known to each and every one of the professionals in the juvenile delinquent system. 
Training should be more consistent throughout the judicial system. Many judges and lawyers do not know that a juvenile who has been transferred to adult court could be relocated back to a juvenile detention center where the adolescent would benefit from possible juvenile rehabilitation approach (PAD, 2006). This is an example that shows the serious need for health and judicial policies that provides consistent funding for training in the detention system. Policies need to specifically promote the training of psychologists, lawyers, social workers, and all the different professionals who provide related services to detainees. One possible pilot program is being considered in Miami Dade. This is a much-needed change in the system since Miami Dade has a disproportionately high rate of detained juveniles sent to adult prisons (Florida Department of Juvenile Justice, 2006).

The present lack of access to substance use treatments in juvenile detention should be addressed by those who develop policies. For example post arrest diversion (PAD) is a national demonstration project that has provided JAC personnel with the ability to deal with juvenile detainees in a non-conventional manner. This intervention recognizes that the health related behavioral problems of these adolescents are multiple (alcohol use, high rate of unprotected sex, low educational attainment) and the intervention needs to be holistic. The PAD program is the result of legislation that recognizes the need to have interventions tailored to the different types of adolescent delinquents. For example, first offenders versus adolescent who have shown recidivism; studies have demonstrated the repetitive offenders present higher health risk behaviors (Lederman, Dakof, Larrea, \& Hua, 2004). However, in the PAD program, first offenders who are detained are evaluated along with their families and the intervention is based on 
the needs of the adolescent and the family instead of basing the intervention on the committed crime. It is possible that the PAD program is pilot testing this primary prevention intervention with primary offenders first before targeting a group with higher recidivism and harder to reach population in the future. It should be noted here that treating adolescents and their families and tailoring interventions based on their individual and families' needs may not be financially possible. Therefore, the lack of resources and policies that regulate the juvenile justice system now are two barriers against implementing the PAD program across all peers, parents and detainees' programs.

Even though the PAD intervention is still under evaluation, its result has shown noticeable improvement in the Miami-Dade County juvenile justice system. The importance of programs with an extensive and holistic evaluation is that these programs are able to determine drug use in more than $80 \%$ of the cases where alcohol or other drug use is a problem (PAD, 2006). Furthermore, this program has demonstrated that it has the ability to increase participants' completion of the criminal activity prevention program and decrease the rate of recidivism (PAD, 2006); which has been shown to be related to high level risky sexual behavior(Lederman et al., 2004).

Additionally, the contrasting results on parental approval to use condoms and less use of condom during vaginal sex from the current study highlight the need for policy requiring HIV/AIDS prevention programs for adolescents within detention centers and outside of these facilities in places such as schools and after school programs with highrisk adolescents. As this study's results have shown, positive sexual attitudes are significantly related to condom use, while knowledge of condom use was not associated 
with less condom use during vaginal sex, higher scores of peer approval was associated with more condom use during vaginal sex. Therefore, at the local level legislators and educators may want to consider making attitudinal changes towards safer sex compulsory part of their drug use prevention programs particularly focusing on attitudes toward healthier and safer sexual behaviors among teenagers. Educating and establishing normative attitudes towards sexual behavior in addition to family involvement in education about sexual behavior are critical protective factors when determining sexual deviant behavior (Vega, Gil, \& Zimmerman, 1993). These factors should continue to be a central part of primary and secondary sexual risk prevention with juvenile detainees.

These prevention policies should also account for cultural differences in the provisions of services. These programs should consider targeting both Latino and White adolescent detainees since both groups, when compared separately to Others, were more likely to engage in oral and anal unprotected sex. Also, more longitudinal research with more representation of Latino populations is needed because it is essential to establish local legislations for the inclusion of more appropriate drug use prevention education programs in detention centers. Although there are initiatives that focus on the relationship among drugs, alcohol use and risky sexual behaviors, more efforts should be undertaken at the state and federal levels to provide funding for intervention programs that recognize the influence of alcohol on risky sexual behavior among adolescents. For sexually active detained adolescents, health assessments such as STD screening and treatment should be mandatory as well as post test counseling. A more formal application of the HBM could be used to study the use of the HPV among detained females. To date, few federal or state funded substance abuse treatment or prevention programs in detention centers 
mandate the provision of services that address both STD and substance use among adolescents.

Implications for Social Work and Public Health Practice

Findings from the current study have potential relevance for clinical social work, for prevention programs, and treatment efforts all aimed at reducing alcohol use, drug use, and risky sexual behaviors (particularly vaginal sex). Primary prevention interventions to reduce sexual risk behaviors for detained adolescents should aim at changing how risky sexual behaviors are evaluated while taking into consideration the race/ethnicity of the participants. For example, one approach that programs could implement is ensuring that pre-adolescents learn to recognize that using alcohol is one important factor that could increase their probabilities of engaging in risky sexual behavior. Educating at-risk pre-adolescents on the dis-inhibitory effects of alcohol use and assisting in their skill and belief development to help them avoid the use of substances may be one effective way to prevent other health risk behaviors. Furthermore, helping adolescents foresee future unwanted implications of risky sexual behaviors such as pregnancy and loss of meaningful relationships may help them adopt healthier behaviors. In terms of the race/ethnicity covariate, Latinos and Whites when compared to Other racial ethnic groups separately were more likely to engage in oral and anal risky sexual behaviors. Perhaps higher levels of alcohol use and other drugs among these subgroups of the study's sample are one of the primary causes of the difference in their risky sexual behavior. Hence programs targeting Latinos and Whites in the Miami Dade area may need to focus more on alcohol and drug use prevention. 
The results of the current study suggest that alcohol use is significantly associated with risky sexual behaviors hence; prevention intervention must include education, skills and attitude changing mechanisms to help adolescents prevent the use of alcohol. One way that these interventions could be implemented is by changing the funding mechanisms that presently may provide financial support for each separate problem. Future requests for proposals and announcements should be written in collaboration by the National Institute of Drug Abuse (NIDA), the National Institute of Child Health and Human Development (NICHD) National Institute of Alcohol Abuse and Alcoholism (NIAAA). Such requests for applications (RFA) and requests for proposals (RFP) would provide a more comprehensive approach to the substance use prevention programs that might well diminish the level of risky sexual behaviors of adolescents. For example, the NICHD could help further investigate the role of peers and family factors that influence risky sexual behaviors.

These interventions might have to develop strategies to evaluate alcohol use and to prevent the use of substances and other behaviors that increase the risks of engaging in risky sexual encounter. As the HBM suggests, learning cues received from people and the environs affect beliefs and attitudes about health behaviors (such as sexual behavior). Therefore, attitudes are significant variables for the reduction of risky sexual behaviors among adolescent detainees. Hence practitioners need to continue implementing interventions where positive attitudes are a central focus. As the results of this study suggest, they may pose a protective factor. Future prevention programs could be guided by a sound theoretical framework such as the health belief model (HBM) which could aid practitioners in guiding adolescents making healthier decisions and find ways to integrate 
condom use into their sexual behaviors. Lastly, social workers particularly in juvenile detention centers need to help educate individuals about the association between their alcohol use and their sexual risk behavior; given that most adolescents do not perceive themselves at risk of acquiring HIV (Ellen, Boyer, Tschann, \& Shafer, 1996).

Many of the interventions proven to be successful among minority adolescents have been comprehensive interventions (DiClemente \& Peterson, 1994). Clinicians may help adolescent detainees, especially racial/ethnic minority teenagers, increase their personal awareness rather than only their general knowledge about HIV infection. Increasing awareness of their behavior and coping strategies that provide the skills for avoiding events that may put them at risk of using drugs and consequently engaging in risky sex should be helpful. As the results of this study showed, having the skills necessary to engage in condom use is not closely tied to using them and therefore, intervention programs must continue to teach these skills but also focus on adolescents' attitudes in general. These interventions may take place during individual or peer group or familial sessions or may be part of outreach programming that is undertaken to recruit and educate adolescents about the effect of alcohol on their sexual behavior. Many of those programs that have proven to be efficient at addressing sexual risk behaviors among adolescents, particularly those who are of racial/ethnic minorities have included skill development training on how to negotiate safer sex and education (DiClemente \& Peterson, 1994).

The relationship between condom use with condom use attitudes could be used in individual and group sessions and specifically in peer education programs. Interventions with young minority women mostly from Latinos and African-American descent have 
been successful at lowering risky sexual behavior after teaching participant negotiation skills and condom use skills (Amaro \& Raj, 2000). Comparable interventions to increase participants' negotiation skills and attitudes toward condoms use could be applicable to detained minority female adolescents similar to the ones who participated in the current study. This knowledge of safe sex negotiation skills could provide valuable information to empower adolescents and teach them the importance of their perception and their peers' attitudes towards condom use. Most interventions to reduce sexual risk behaviors among detained adolescents focus on the individual. Although this approach may place a considerate burden on the adolescents, this may be necessary and unavoidable given that some of these adolescents may not have a close relationship with their parents. Therefore, due to their social and developmental stage, these adolescents may not receive most of their influence by their parents but may be highly influenced by their peers before and during being institutionalized in a detention center (DiClemente \& Peterson, 1994).

From a social work practice perspective, evidence of high sexual risk behaviors among alcohol using adolescent detainees highlights the need to implement effective prevention programs. One of the features of an effective risky sexual prevention program has been the adolescents' reported connection with their mentors or teachers. Voisin et al. (2004) documented that the lower the teacher-adolescent connection, reported by the adolescent detainees, the higher the risk of substance use, risky sexual behaviors and multiple sexual partners. That study analyzed data from 550 detained adolescents using audio-computerized interviews with the assistance of a master level interviewer (Voisin et al. 2004). Therefore, efforts must be undertaken to retrain social workers whenever appropriate to reach out to adolescents and to mentor them. Additionally, social workers 
may start to focus on their mentor role to help detained adolescents adopt healthy sexual behaviors. Given detained adolescents' low educational level and possible taboos against being a sexually active adolescent, social workers may need to cultivate an older peer relationship through individual sessions and group work with these adolescents so they can provide accessible role models and build rapport and trust.

Many of these detained adolescents are truant and school programs may not reach the ones who most need them. Interventions in juvenile detention centers could work along with community service organizations that could provide health risk behavior prevention services when adolescent detainees find themselves released into the community. This arrangement is recommended since many times the detentions centers may not have the personnel or infrastructure to provide education and counseling. Another limitation with the present juvenile detention system is that some of the detainees are returned to their communities without receiving any help in that setting to re-direct their behavior and explore their issues with substance use or risky sexual behavior. Practitioners must develop a strategy to help detained adolescents reconstruct healthy behaviors.

An example of the number of adolescent delinquents who return to the community without proper follow up is that in the fiscal year 2004-2005 the Florida Department of Justice processed 95, 263 delinquent juveniles and only 8,992 were sent to juvenile treatment centers (Juvenile Assessment Center, 2004). Although there is strong support from an Advocacy Project, these figures reveal that a large number of adolescents were transferred to adult courts. This situation has created a crisis in Miami-Dade and has left detained adolescents without proper prevention interventions for substance use, HIV, 
and other STD. As the current dissertation results indicate, detained adolescents may benefit from disease prevention education and skill building interventions that would not be available to them if they were processed in adult courts.

Implications for Future Research

The current study sample was predominantly male, making it difficult to generalize results to female detainees. This situation may have occurred because of the sampling method. It suggests that future research should focus more on recruiting females and the prevalence of sexual risk behaviors and substance use among adolescent female detainees. Adolescent females have typically been under-represented in these types of studies. Future studies should also further examine race/ethnicity and other factors that have been shown to be important for adolescent females, influencing things such as age at onset of sexual activity and history of sexual abuse and molestation (Kirby, 2001). A better knowledge base concerning possible differences between risky sexual behaviors and sexual experience among adolescent males and females may help researchers and practitioners further tailor prevention programs.

Although the current study's results regarding gender and its relationship with condom use differ from the researcher's expectations, this concept should continue to be thoroughly studied since there may be other gender related sources of reinforcements to action that may be significant for adolescent detainees. These results also suggest the future use of more comprehensive measures of approval of condom use among males and females. Future research should measure not only the perceived but also the actual encouragement to use condoms that is spread through open communication among parents, peers, and the study's participants. This will be a more accurate measure of the 
variable since it will provide the opportunity to ascertain any difference between the actual encouragement to use condoms and the perceived one. Learning about the actual approval that male and female adolescents receive and how they perceive it warrants further study since it will help prevention intervention research.

Future studies should consider a more longitudinal approach to the study of sexual risky behavior among at risk adolescents; such methods may allow researchers to learn more about the development of those behaviors. Learning about the process in which adolescents learn those behaviors may help practitioners teach and stimulate adolescents to replace those unhealthy behaviors, beliefs and attitudes with more positive ones. These longitudinal studies may have to be done in collaboration with schools and community organizations with at risk populations; given that adolescents typically need multiple and consistent healthy behaviors stimuli before they adopt those behaviors. Lastly, longitudinal studies would benefit from using more sophisticated measures of parental and peer approval of condom use or other proxy to measure cues to action.

Since the average age of first sexual intercourse is 12 years of age for the juvenile delinquent population, longitudinal research intervention studies should also address preadolescents. In addition, for young detained adolescents, future research intervention should evaluate the possibility of teaching them healthy behaviors during their tenure in detention and administering longitudinal follow up. It is imperative that future longitudinal research focus on the acquisition and development of risky health patterns to prevent releasing the detained adolescents to their communities without receiving rehabilitative assistance. 
Both peer and parental support for condom use need to be further investigated among the detained population. Some researchers continue to believe that future secondary prevention interventions could benefit from including mentors and family inclusive programs (Juvenile Assessment Center, 2006). The current study's researcher suggests that future studies should include not only knowledge of HIV transmission, but also beliefs and attitudes about other significant health risk behaviors associated with the use of alcohol and other drugs. Since there is such a significant relationship among the use of alcohol and other drugs and sexually risky behaviors, it is imperative for prevention interventions to target peers' beliefs and attitudes toward substance use and risky health behaviors. Adolescents' attitudes towards substance use may place them at risk of using drugs hence increasing the chances of engaging in unprotected sex and exposure to HIV and other STD.

More research will be done in the future to examine how other health risk taking behaviors may be related to the adolescents' experiences with alcohol and other drug use. For example, other risky health behavior patterns that may be found among these minority adolescent detainees are poor nutrition and ill preventive physical health care patterns. Perhaps substance use and risky sexual behavior prevention may need to become a required component of the detained adolescents' health care coordination. The process as well as the outcome evaluation of that intervention would shed some light on the subject, helping practitioners and law makers.

On this researcher's agenda there is also a plan to examine the relationship among health dietary patterns, risky sexual behaviors, and substance use among Latino female 
adolescents in the Miami Dade area. As the HBM posits, health behaviors including long term behavioral patterns are affected by the individual's beliefs and attitudes. Therefore, they are very difficult to change and they all require a complex set of interventions to create changes among public health programs' participants.

To continue evaluating and developing empirically-based informed preventive interventions to improve the health behaviors of adolescent detainees is also another future project. This researcher's future studies will also focus on the relationship between condom use and adolescents' age. Future studies will also include further examination of statistically significant covariates from the present study in a hypothesis testing model. The results in this study suggest that more than a third of the participants used condoms every single time and although age was not significantly related to condom use, it has been documented that adolescents are more likely to use condoms during their first sexual encounter and that condom use decreases as they get older (Ku, Sonenstein, \& Pleck, Nov-Dec. 1994). If condom use decreases with age regardless of the perception of partners' being at high risk for STD infection, as some researchers have documented $(\mathrm{Ku}$ et al, , Nov-Dec. 1994), would use pattern be the same throughout the different race/ethnic adolescent groups?

Based on the current study's findings, future research may focus on investigating if there are any specific protective factors among African-American adolescents and other racial/ethnic groups that showed low risk behaviors despite having similarities with Whites and Latinos detained adolescents in the Miami Dade area. What are the similarities among Whites and Latinos in the Miami area and what would be the most 
appropriate intervention programs for such a group? Is there a developmental or a social protective factor among African-American detainees in Miami-Dade?

In addition, perhaps future studies would benefit from collecting more in-depth data on sexual partners since the norms and beliefs of these individuals have been said to influence adolescent's behavior (Kirby, 2001). By examining the concepts (social and cultural) that need to be integrated into a future model to study risky sexual behavior, it is evident that future researchers should draw from different theories to help further clarify such a complex behavior.

\section{Summary}

The results from the current study clearly show the significant association among detained adolescents alcohol use, drug use and sexual risk behaviors. Alcohol use was shown to be the driving behavior with its effect on risky sex. Similarly significant were the condom use attitudes and the level of HIV knowledge among participants. Although a larger sample will help clarify what racial/ethnic factors may have an effect on risky sexual behavior, in the current study, in general, there was a statistical significant relationship between race/ethnicity (factors) and risky sexual behavior.

Similarly, sexually transmitted diseases were not significant in the analysis until race/ethnicity was controlled for in the regression. Further research is warranted to help clarify that relationship. Although this study offers unique information that partially helped answer the research questions, there are also more questions such as if the STD history has a stronger effect on condom use only among particular racial/ethnic groups. In sum, based on this research, condom use among adolescent detainees could be impacted 
by interventions that target alcohol use, drug use, and condom use attitudes in their primary and secondary prevention plans. The problem of STD among adolescents in general, its apparent relationship with substance use, and the numbers of adolescents who engage in risky sexual behavior strongly underscore the need for more research and more effective prevention interventions for this population. 


\section{LIST OF REFERENCES}

Amaro, H., \& Raj, A. (2000). On the margin: Power and women's HIV risk reduction strategies. Sex Roles(Special issue).

American Academy of Pediatrics. (2001). Condom Use by Adolescents. Pediatrics, 107(6), 1463-1469.

Bandura, A. (1994). Social cognitive theory and exercise of control over HIV infection. In R. J. DiClemente \& J. Peterson, L. (Eds.), Preventing AIDS: Theories and methods of behavioral interventions (pp. 25-59). New York: Plenum Press.

Brener, N. D., Billy, J. O., \& Grady, W. R. (2003). Assessment of factors affecting the validity of self reported health-risk behavior among adolescents: Evidence from the scientific literature. Journal of Adolescent Health, 33, 436-457.

Canterbury, R. J., McGarvey, E. L., Sheldon-Keller, A., E., \& Reams, P. (1995). Prevalence of HIV-related risk behaviors and STDs among incarcerated adolescents. Journal of Adolescent Health, 17, 173-177.

Center for Disease Control, \& National Center for HIV STD and TB Prevention. (2004). STDs in persons entering corrections facilities. Retrieved August 29, 2004, from htpp://www.cdc.gov/std/stats01/2001SFCorrections.htm

Center for Disease Control and Prevention. (2000). Surveillance Report (No. 11). Atlanta, GA: Center for Disease Control Division of HIV/AIDS.

Center for Disease Control and Prevention. (2001, June 8). Morbidity and mortality weekly report. Retrieved March 31, 2004, from www.cdc.gov/mmwr/preview/mmwrhtml/mm5021a2.htm

Center for Disease Control and Prevention. (2002). Morbidity and Mortality Weekly Report (No. SS-4). Atlanta: Center for Disease Control and Prevention.

Center for Disease Control and Prevention. (2006, October 5, 2004). How Effective Are Latex Condoms in Preventing HIV? Retrieved April 27, 2006, from http:www.cdc.gov/hiv/pubs/faq-condom.htm

Center for Disease Control and Prevention, \& National Center for HIV/STD and TB prevention. (2004, June 28). STDs in adolescents and young adults. Retrieved August 29, 2004, from http://www.cdc.gov/std/stats01/2001SFAdol\&YAdults.htm 
Center for Disease Control and Prevention National Center for HIV STD and TB prevention. (2003). Profile of a nation's health. Retrieved February 12,2003, 2003, from www.cdc.gov/maso/factbook/main/htm

Center for Disease Control and Prevention National Center for HIV STD and TB prevention. (2004, June 28). STDs in the south. Retrieved August 29, 2004, from http://www.cdc.gov/std/stats01/2001SFSouth.htm

Center for Disease Control Division of HIV/AIDS Prevention. (2000). Surveillance Report (No. 11). Atlanta, GA: Center for Disease Control.

Center for Disease Control Division of HIV/AIDS Prevention. (2001, November 9). Revised guidelines for HIV counseling, testing, and referral. Retrieved January 6, 2004, from http://www.cdc.gov/mmwr/preview/mmwrhtml/rr5019a1.htm

Center for Disease Control Division of HIV/AIDS Prevention. (2002a). HIV/AIDS surveillance report. Atlanta, GA: Centers for Disease Control And Prevention.

Center for Disease Control Division of HIV/AIDS Prevention. (2002b). Morbidity and Mortality Weekly Report (No. Vol. 51, No. 27). Atlanta, GA: Center For Disease Control and Prevention.

Coleman, L., M., \& Cater, S., M. (2005). A qualitative study of the relationship between alcohol consumption and risky sex in adolescents. Archives of Sexual Behavior, 34(6), 649-661.

Cottler, L. B., Helzer, J. E., \& Tipp, J. E. (1990). Lifetime patterns of substance use among general population subjects engaging in high risk sexual behaviors: Implications for HIV risk. American Journal of Drug and Alcohol Abuse, 16, 207216.

Crosby, R., A., DiClemente, R. J., Wingood, G. M., Cobb, B., K., Harrington, K., Davies, S., L., Hook, E., W., \& Oh, K., M. (2002). Condom use and correlates of African American adolescent females' infrequent communication with sex partners about preventing sexually transmitted diseases and pregnancy. Health Education and Behavior, 29(2), 219-231.

D'angelo, L., \& DiClemente, R. (Eds.). (1996). Sexually transmitted diseases including human immunodeficiency virus infection. NY: Plenum Press.

Dembo, R., Schmeidler, J., Chin Sue, C., \& Borden, P. (1998). Psychological, substance use, and delinquency differences among Anglo, Hispanic White, and African American male youths entering a juvenile assessment center. Substance Use and Misuse, 33(7), 1481-1510. 
Dembo, R., Williams, L., La voie, L., Schmeidler, J., Kern, J., Getreu, A., \& al., e. (1990). A longitudinal study of the relationships among alcohol use, marijuana/hashish use, cocaine use, and emotional/psychological functioning problems in a cohort of high risk youth. The International Journal of the Addictions, 25(11), 1341-1382.

Devieux, J., Malow, R. M., Ergon-Perez, E., Samuels, D., Rojas, P., Khushal, R., et al.. (2005a). A comparison of African American and Cuban American adolescent juvenile offenders: Risky sexual and drug behaviors. Journal of Social Practice in the Addictions, 5,, 69-83.

Devieux, J., Malow, R. M., Ergon-Perez, E., Samuels, D., Rojas, P., Khushal, R., et al., (2005b). A comparison of African American and Cuban American adolescent juvenile offenders: Risky sexual and drug behaviors. In M. De La Rosa, L. Holleran \& L. Straussneer (Eds.), Substance abusingLatinos: Current research on epidemiology, prevention, and treatment. New York: The Harwoth Press.

Voisin, D.R., Salazar, L.F., Crosby, R., Diclemente, R., J., Yarber, W.,L., Staples-Horne, M. (2004). Teacher connectedness and health-related outcomes among detained adolescents. Journal of Adolescent Health, 37, (4), 337-352.

DiClemente, R. J., Lanier, M. M., Horan, P. F., \& Lodico. (1991). Comparison of AIDS knowledge, attitudes, and behaviors among incarcerated adolescents and a public school sample in San Francisco. American Journal of Public Health, 81, 628-630.

DiClemente, R. J., \& Peterson, J. L. (Eds.). (1994). Preventing AIDS: Theories and methods of behavioral interventions. New York: Plenum Press.

DiClemente, R. J., Wingwood, G., M., Crosby, R., Cobb, B., K., Harrington, K., \& Davies, S., L. (2001). Parent-adolescent communication and sexual risk behaviors among African American adolescent females. Journal of Pediatrics, 139, 407412.

Ellen, J. M., Boyer, C. B., Tschann, J. M., \& Shafer, M.-A. (1996). Adolescents' Perceived Risk for STDs and HIV Infection. Journal of Adolescent Health, 18 (3), $177-181$.

Education Training Research Associates (2004). Becoming a responsible teen. Retrieved March 3, 2005, from http://www.etr.org/recapp/programs/teen.htm

Fishbein, M., \& Guinan, M. (1996). Behavioral Science and Public Health: A necesary partnership for HIV prevention. Public Health Reports, 111, 5-10. 
Fishbein, M., Triandis, H., C., Kanfer, F., H., Becker, M., Middlestadt, S., E., \& Eichler, A. (1991). Factors Influencing Behavior and Behavior Change. Paper presented at the NIMH Theorists Workshop, Washington, D.C.

Florida Department of Health. (2003). Florida HIV/AIDS annual report 2003.

Tallahassee: Florida Department of Health.

Florida Department of Health. (2004). Bureau of STD control and prevention report. Tallahasee: Florida Department of Health.

Florida Department of Health. (2004, p. 3-4). Florida HIV/AIDS annual report/epidemiologic profile 2004 [Electronic]. Tallahassee: Florida Department of Health.

Florida Department of Juvenile Justice. (2006). Juvenile detention center information. Retrieved January 05, 2006, from http://www.djj.state.fl.us/Research/Trends.html.

Florida Department of Public Health. (2004). HIV and AIDS among adolescents \& young adults in florida. Retrieved August 30, 2004, from http://www9.myflorida.com/disease_ctrl/aids/index.html

Fromme, K., D'Amico, E., J., \& Katz, E., C. (1997). Intoxicated sexual risk taking: an expectancy or cognitive impairment explanation? Journal of Studies on Alcohol, $60(1), 54-63$.

Gibson, D. R., \& Young, M. (1994). Assessing the reliability and validity of selfreported risk behavior (No. Report 94-3750). Rockville: NIH -US Department of Health And Human Services.

Grumbaum, J. A., Kann, L., Kinchen, S., A., Ross, J., G., Gowda, V., R., Collins, J., L., \& Kolbe, L., J. (2000). Youth risk surveillance national alternative high school youth risk behavior survey. Journal of School Health, 70(1), 5.

Inciardi, J. A. (1996). HIV risk reduction and service delivery strategies in criminal justice settings. Journal of Substance Abuse Treatment, 13(5), 421-428.

Irwin, J., Charles, E., Burg, S. J., \& Uhler-Cart, C. (2002). America's adolescents: Where have we been, where are we going? Journal of Adolescent Health, 31(6, Supp. 1), 91-121.

Jemmott, J., Jemmott, L., \& Fong, G., T. (Eds.). (2000). HIV behavioral interventions for adolescents in community settings. New York: Kluwer Academic/Plenum..

Juvenile Assessment Center. (2004, July 7). About us. Retrieved September 9, 2004, from www.miamidade.gov/JAC/about.asp 
Juvenile Asessment Center. (2006, June 29, 2004). Screening and Assessment. Retrieved March 23, 2006, from http://www.miamideade.gov/JAC/screening.asp

Kalichman, S. C., Stein, J. A., Malow, R. M., AverHart, C., Devieux, J., Jennings, T. J., et al. (2002). Predicting protected sexual behaviour using the informationmotivation-behavior skills model among adolescent substance abusers in court ordered treatment. Psychology, Health \& Medicine, 7(3), 326-338.

Kingree, J. B., \& Betz, H. (2003). Risky sexual behavior in relation to marijuana and alcohol use among african-american, male adolescent detainees and their female partners. Drug and Alcohol Dependence, 72(2), 197-203.

Kingree, J. B., Braithwaite, R., \& Woodring, T. (2000). Unprotected sex as a function of alcohol and marijuana use among adolescent detainees. Journal of Adolescent Health, 27(3), 179-185.

Kingree, J. B., \& Phan, D. L. (2001). Marijuana use and HIV risk among adolescent offenders: The moderating effect of age. Journal of Substance Abuse, 13(1-2), 5971.

Kipke, M. D. (1999). Risks and opportunities: Synthesis of studies on adolescence. Retrieved January 19, 2006, from http://books.nap.edu/htlm/risks_opportunities

Kirby, D. (2001). Understanding what works and what doesn't in reducing adolescet sexual risk-taking.Unpublished manuscript.

Kolbe, L. J. (1987). The application of health behavior research: Health education and health promotion. In D. Gochman, S. (Ed.), Health Behavior: Emerging Research Perspectives (pp. 381-396). Atlanta, GA: Plenum Press.

Ku, L., Sonenstein, F. L., \& Pleck, J. H. (Nov-Dec. 1994). The dynamics of young men's condom use during and across relationships. Family Planning Perspectives, 26(6), 246-251.

Lederman, C. S., Dakof, G. A., Larrea, M. A., \& Hua, L. (2004). Characteristics of adolescent females in juvenile detention. International Journal of Law and Psychiatry, 27, 321-337.

Lescano, C., M., Vazquez, E., A., Brown, L., K., Litvin, E., B., Pugatch, D., \& Group, P., S., S., (2006). Condom use with casual and main partners: whats's in a name? Journal of Adolescent Health 39. 443-447

Lescano, C., M., Vazquez, E., A., Brown, L., K., Litvin, E., B., Pugatch, D., \& Group, P., S., S., (2006b). Condom use with casual and main partners: whats's in a name? Journal of Adolescent Health 39. 443-447 
Lucenko, B. A., Malow, R. M., Martinez-Sanchez, M., Jennings, T. J., \& al., e. (2003). Negative affect and HIV risk in alcohol and other drug (AOD) abusing adolescent offenders. Journal of Child \& Adolescent Substance Abuse, 13(1), 1-17.

Lux, K., M., \& Petosa, R. (1994). Using the Health Believe Model to predict safer sex intentions of incarcerated youth. Health Education Quarterly, 21(4), 487-497.

MacCoy, C., B., \& Inciardi, J., A. (1995, p.129). Sex, drugs and the continuing spread of AIDS. Los Angeles, CA: Roxbury Publishing Company.

Magura, S., Shapiro, J., L., Kang, S., Y. (1994).Condom use among criminally involved adolescents. Aids Care. 6 (5) 595-603.

Malow, R. M., Devieux, J., Jennings, T. J., \& Lucenko, B. (2001). Substance abusing adolescents at varying levels of HIV risk: Psychosocial characteristics, drug use and sexual behavior. Journal of Substance Abuse Treatment, 13, 103-117.

Malow, R. M., Rosemberg, R., \& Devieux, J. (2006). Prevention of infection with human immunodeficiency virus in adolescent substance abusers. In H. Liddle \& C. Rowe (Eds.), Adolescent Substance Abuse: Research and Clinical Awareness (pp. 284309). Cambridge, Boston: Cambridge University Press.

Markham, C., M., Tortolero, S., R., Escobar-Chavez, L., S., Parcel, G., S., Harris, R., \& Addy, R., C. (2003). Family connectedness and sexual risk-taking among urban youth attending alternative high schools. Perspectives on Sexual Reproductive Health, 35(4), 174-179.

McCoy, C. B., \& Inciardi, J. A. (1995). Sex, drugs, and the continuing spread of AIDS. Los Angeles, CA: Roxbury Publishing Company.

Miami Dade County Health Department (2006). Number of reported AIDS and HIV cases (no.2005). Miami:Miami Dade County Health Department.

Miami Dade County Health Department (2006b). Number of reported AIDS and HIV cases (no.2005). Miami:Miami Dade County Health Department

Miami Dade Regional Juvenile Detention Center. Bureau of quality assurance: Program review report. Retrieved Agust 19, 2006, from http://www.djj.state.fl.us/QA/programreports/detention2005/dade.pdf.

McLeroy, K., R., Bilbeau, D., Steckler, A., \& Glanz, k. (1988). An Ecological Perspective on Health Promotion Programs. Health Education Quarterly, 15(4), 351-377. 
Morris, R. E., Harrison, E. A., Knox, G. W., \& Tromanhauser, E. (1995). Health risk behavioral survey from 39 Juvenile correctional facilities in the united states. Journal of Adolescent Health, 17(6), 334-344.

National Cancer Institute. (2005). Theory at a glance: A guide for health promotion practice (U.S. Department of Health and Human Services Report No. II). Washington, D.C.: National Institutes of Health.

Pantin, H., Prado, G., Schwartz, J., \& Summer, S. (2005). Methodological challenges in designing efficacious drug abuse and HIV preventive interventions for Hispanic adolescent subgroups.Journal of Urban Health: Bulletin of the New York Academy of Medicne.82(2), 92-102

National Institute of Allergy and Infection Diseases. (2005, July 2005). HIV Infection in adolescents and young adults in the U.S. Retrieved January 18, 2006, from http://www.niaid.nih.gov/factsheets/hivadolescent.htm

Pinkerton, S. D., \& Abramson, P. R. (1997). Effectiveness of condoms in preventing HIV transmission [Electronic version]. Society of Scientific Medicine, 44(9), 13031312.

Robertson, A., Stein, J., A., \& Baird-Thomas, C. (2006). Gender differences in the prediction of condom use among incarcerated juvenile offenders: testing the information-motivation-behavior skills (IMB) model. Journal of Adolescent Health, 38(1), 18-25.

Rosenstock, I., M. (1974). The Health Belief Model and Preventive Health Behavior. Health Education Monograph, 2(4), 354-385.

Rosenstock, I. M. (1974). Historical origins of the health belief model. Health Education Monographs, 2(4), 328-335.

Rosenstock, I. M., Strecher, V. J., \& Becker, M. H. (1988). Social Learning Theory and the Health Belief Model. Health Education Quarterly, 15(2), 175-183.

Rosenstock, I. M., Strecher, V. J., \& Marshall, B. H. (1994). The health belief model and HIV risk behavior change. In R. J. DiClemente \& J. Peterson, L. (Eds.), Preventing AIDS (pp. 5-24). New York: Plenum Publishing Corp.

Rotheram-Borus, M. J. (2000). Expanding the range of interventions to reduce HIV among adolescents. AIDS, 14(33-40). 
Shumacher, J., E., Milby, J., B., Engle, M., Raczynski, J., M.(2000). Linking practice and science in the substance abuse treatment of homeless persons. Journal of Applied Behavioral Science. 36(3), 297-313

Singer, J., D., \& Willet, J., B., (2003). Applied longitudinal data analysis. New York: Oxford University Press.

Sinoean, C., DiClemente, R. J., Wingood, G. M., Crosby, R., Cobb, B., K., Harrington, K., Davies, S., L., Hook, E., W., \& Oh, K., M. (2002). Psychosocial and behavioral correlates of refusing unwanted sex among african american adolescent females. Journal of Adolescent Health, 30, 55-63.

Sohler, N., Colson, P. W., Meyer-Bahlburg, H. F. L., \& Susser, E. (2000). Reliability of self-reports about sexual risk behavior for HIV among homeless men with severe mental illness. Psychiatry Service, 51(6), 814-816.

Sonya, T. (2004, p.8). Shades of Belonging [Electronic version]. Washington, D.C.: PEW Hispanic Center.

SPSS. (2003). SPSS Smartview (Version 12.0). Chicago, Illinois: SPSS Inc.

Sterk, C. E. (2002). The health intervention project: HIV risk reduction among african american women drug users. Public Health Reports, 117(Supp. 1), s89-s95.

St. Lawrence, J., Jefferson, E., A., \& Brasfield, T., L., (1995). Comparison of eduation versus behavioral skills training interventions in lowering sexual HIV-risk behavior of sbustance dependent adolescents. Journal of Consulting and Clinical Psychology. 63 (1), 154-157.

Tabachnick, B. G., \& Fidell, L. S. (1996). Using multivariate statistics (4th ed.). Needham Heights: Allyn \& Bacon.

Tapert, S., F., Aarons, G., A., Sedlar, G., R., Brown, S., A. (2001). Adolescent substance use and sexual risk taking behavior. Journal of Adolescent Health. (28) 181-189.

Teplin, L. A., Mericle, A. A., McClelland, G. M., \& Abram, K. M. (2003). HIV and AIDS risk behaviors in juvenile detainees: implications for public health policy. American Journal of Public Health, 93(June), 906-912.

United States Census. (2000). Census 2000 summary file 1 (SF 1) 100-percent data. Retrieved September 15, 2004, from http://factfinder.census.gov 
Vega, W. A., Gil, A. G., \& Zimmerman, R. S. (1993). Patterns of drug use among CubanAmerican, African-American, and white non-Hispanic boys. Am J Public Health, 83(2), 257-259.

Villaruel, A. M., \& Rodriguez, D. (2003). Beyond stereotypes: Promoting safer sex behaviors among latino adolescents. Jounal of Obstetric Gynecology and Neonatal Nursing, 32(2), 258-263.

Wallace, J. M., Bachman, J. G., O'Malley, P. M., Schulenberg, J. E., Cooper, S. M., \& Johnston, L. D. (2003). Gender and ethnic differences in smoking, drinking and illicit drug use among American 8th, 10th and 12th grade students, 1976-2000. Addiction, 98(2), 225-234.

Weinhardt, L. S., Forsyth, A. D., Carey, M. P., \& Jaworski, B. C. (1998). Reliability and validity of self report measures of HIV-related sexual behavior: progress since 1990 and recommendations for research and practice. Achives of Sexual Behavior, 27(2), 155-180.

William Stern et al. (2001). Ryan white Title I: Needs assessment 2001. Miami, FL: William Stern \& Associates. 
VITA

\section{PATRIA ROJAS}

2003-present

2000

$1999-2001$

1999

$1998-1999$

$1997-1998$

1995

$1991-1995$
Women's Study Assistant Director Latino Drug Abuse Research Center School of Social Work, Justice and Public Affairs Florida International University, Miami, FL

M.P.H., Concentration in Maternal and Child Health Boston University, Boston, MA

Consultant / Project Coordinator Health Services Division

John Snow, Inc., Boston, MA

M.S.W., Concentration in Macro Social Work

Boston University, Boston, MA

Social Work Intern

Bureau of Family and Community Health

Maternal and Child Health Unit

Massachusetts Department of Public Health

Boston, MA

Social Work Intern

Pediatrics Department

Boston Medical Center, Boston, MA

B.A. in Biology

Merrimack College, North Andover, MA

HIV/AIDS Educator

Greater Lawrence Family Health Center

Lawrence, MA

\section{SELECTED PROFESSIONAL PRESENTATIONS AND PUBLICATIONS}

De La Rosa, M., Rugh, D., \& Rojas, P. (2005) Substance abuse among Puerto Rican and Dominican gang members in a small city setting. Journal of Social Work Practice in the Addictions, 5(1/2), 21-43.

Devieux, J., Malow, R., Ergon-Pérez, E., Samuels, D., Rojas, P., Khushal, R., \& JeanGilles, M. (2005). A comparison of African American and Cuban American adolescent juvenile offenders: Risky sexual and drug behaviors. In M. De La 
Rosa, L. Holleran, \& L. Straussneer (Eds.), Substance abusing Latinos: Current research on epidemiology, prevention and treatment. New York: Haworth Press.

Rojas, P. (2000, April). Development of a women's primary health care assessment tool. Paper presented at the Boston University Maternal and Child Health Faculty Colloquium. Boston, MA.

Rojas, P. (2002, August). The link between HIV and substance abuse. Presented to military judges and members of La Primera Brigada Militar de Barranquilla, Barranquilla, Colombia.

Rojas, P. (2003, October). Meta analysis of effective HIV prevention interventions for Latino women 1995-2002. Paper presented at the Florida International University School of Nursing: Improving Health Care Quality through Research, Miami, FL.

Rojas, P., Hamann, M., De La Rosa, M. (2004, October). How to measure transmission of drug use among Latino women. Poster presented at the National Hispanic Science Network on Drug Abuse: A Roadmap for Hispanic Drug Abuse Research, San Antonio, TX.

Rojas, P. (2005, February). Collecting data from drug using Latino women: Challenges. Presentation at Florida International University's Latino Drug Abuse Research Center First Annual Conference. Miami, FL

\section{HONORS AND AWARDS}

- National Hispanic Science Network Graduate Member (2004-present)

- American Public Health Association Graduate Member (2005- present)

- Maternal and Child Health Bureau Leadership grant (1999, 2000)

- Boston University Legacy For The Future Academic Scholarship (1998)

- Boston University Mary Louise Dillon Academic Scholarship (1998)

- Merrimack College Senior Role Model (1995)

- Merrimack College Office of Student Affairs Community Service Medal (1995)

- Merrimack College A.T.C. Full Academic Scholarship (1992-1995) 